\title{
The Trading Volume Impact of Local Bias: Evidence from a
}

\author{
Natural Experiment
}

Heiko Jacobs and Martin Weber*

June 1, 2011

Review of Finance, forthcoming

Appendix attached

\begin{abstract}
Exploiting regional holidays in Germany as a source of exogenous cross-sectional variation in investor attention, we provide evidence that the well-known local bias at the individual level materially affects stock turnover at the firm level. Stocks of firms located in holiday regions are temporarily strikingly less traded than otherwise very similar stocks in non-holiday regions. This negative turnover shock survives comprehensive tests for differences in information release. It appears particularly pronounced in stocks less visible to non-local investors, and for smaller stocks disproportionately driven by retail investors. Our findings contribute to research on local bias, trading activity, and investor distraction.
\end{abstract}

Keywords: Local bias, trading activity, investor distraction, holiday effect, natural experiment

JEL Classification Codes: G12, G14

*Heiko Jacobs is from the Lehrstuhl für Bankbetriebslehre, Universität Mannheim, L 5, 2, 68131 Mannheim. E-Mail: jacobs@bank.bwl.uni-mannheim.de. Martin Weber is from the Lehrstuhl für Bankbetriebslehre, Universität Mannheim, L 5, 2, 68131 Mannheim, and CEPR, London. E-Mail: weber@bank.bwl.uni-mannheim.de. Mark Seasholes and an anonymous referee provided many constructive suggestions that considerably improved the paper. We thank seminar participants at the 17th Annual Meeting of the German Finance Association (DGF), at the 9th Cologne Colloquium on Financial Markets, at the 14th Conference of the Swiss Society for Financial Market Research (SGF), and at the University of Mannheim for valuable comments. We would like to thank Alexander Hillert for excellent research assistance. Financial support from the Deutsche Forschungsgemeinschaft (SFB 504) and the Hamburg Stock Exchange is gratefully acknowledged. 


\section{Introduction}

By now there is ample evidence that both private and professional investors have a strong preference for trading stocks of locally-headquartered firms. But is this so-called local bias strong and pervasive enough to matter for the cross-section of stock turnover at the firm level? To answer this question, we run a natural experiment in the German stock market.

Germany has several holidays which are observed only in some of its 16 states. While these holidays have a religious origin, they materially influence public life as a whole. Authorized by law, they are characterized by a limit or ban on work and official business (but not exchanges). Previous research (e.g. DellaVigna and Pollet (2009), Hong and Yu (2009), and Frieder and Subrahmanyam (2004)) and casual evidence suggest that both private and professional investors in holiday regions tend to be temporarily distracted and thus to often refrain from actively participating in the stock market on such days.

This exogenous variation in investor attention along a geographical line would not have implications for the cross-section of abnormal firm-level trading activity if investors traded the market portfolio. Only the aggregate level of trading volume might then be affected (e.g. Lo and Wang (2000)). However, the introduction of local bias gives rise to a crosssectional hypothesis untested so far: Stocks of firms located in holiday regions (in the following referred to as holiday firms) should, all else equal, exhibit a more pronounced negative shock in trading activity than stocks of firms located in unaffected regions (in the following referred to as non-holiday firms). An advantage of the German setting is that both samples are similar and thus satisfy the requirements of a natural experiment: They are broadly homogenous with respect to e.g. the number of firms, industry composition, typical firm size, average stock risk-return profiles or (unconditional) turnover properties. Similar findings apply to important characteristics of individual investors.

Consistent with our line of reasoning, we indeed find that holiday firms are (only) temporarily strikingly less traded, both in statistical and economic terms. The negative shock in turnover relative to non-holiday firms ranges roughly from $10 \%$ to $20 \%$. It is not affected by the inclusion of various control variables or several changes in methodology.

To the extent that news arrival triggers abnormal trading, one might be concerned that 
our findings could be driven by a temporary change in the cross-section of information release. Note, however, that the vast amount of firm-relevant news on a market, industry, style or other aggregated levels should not be affected by regional holidays. It is arguably only the structure of idiosyncratic firm-specific news, generated in or near a firm's headquarter, which might potentially be affected. Digging deeper, we explore this news-based explanation of our findings from five perspectives. From a firm perspective, we analyze shocks in the release of corporate news. From a market perspective, we study shocks in the idiosyncratic component of stock returns. From an investor's viewpoint, we explore shocks in the search frequency for firm names in Google. From an analyst perspective, we study shocks in the cross-section of stock recommendations. From a media point of view, we analyze shocks in press coverage. Overall, these tests (only) sporadically point to significant differences in information release. Thus, we cannot rule out the possibility of lower information intensity for holiday firms contributing to our results. However, we believe it is justified to argue that information effects are unlikely to fully explain the magnitude and robustness of the findings we document.

In line with a local bias explanation and the investor recognition hypothesis of Merton (1987), the regional holiday effect is particularly pronounced for firms less visible to nonlocal investors. Market capitalization, idiosyncratic risk and residual media coverage are used as proxies for visibility. Finally, we study daily trading patterns of about 3,000 private investors from a German online broker. Consistent with implications of previous research, individual investors seem to disproportionately cause the negative turnover shock in smaller firms, in which their localized trading is concentrated.

Our study contributes to the literature in several ways. First, while prior research shows that investors are biased towards the stocks of nearby firms, we identify scenarios in which these individual preferences are strong and pervasive enough to materially affect the crosssection of stock turnover. To our knowledge, our novel approach thereby provides the first non-US evidence of local bias affecting market outcomes.

Second, our findings help to better understand determinants of stock-level trading volume, which plays an essential role in much research on liquidity, return predictability, behavioral finance or information asymmetries. For example, Hong and Stein (2007) note that "many of most interesting patterns in prices and returns are tightly linked to movements in 
volume" (p. 111). At the same time, empirical evidence on the drivers of its substantial variation both in the cross-section and time-series is scarce (see e.g. the discussions in Gao and Lin (2010), Statman et al. (2006) or Chordia et al. (2007)). We add to this literature by uncovering cross-sectional regularities related to firm location, firm visibility, and investor clienteles.

Third, a growing body of research builds on the idea of limited attention, whereby investors process only a subset of publicly available information due to attention capacity constraints. A challenge for empirical work is the identification of a suitable proxy for investor distraction. For example, Hou et al. (2009) rely on down market periods, while Hirshleifer et al. (2009) employ the number of competing earnings announcements. In a scenario related to ours, DellaVigna and Pollet (2009) analyze the market response to earnings announcements on Fridays, when, as they argue, investor inattention is more likely. Our findings highlight the role of regional holidays as a promising proxy for limited attention. We identify scenarios which seem to cause distraction of an important subset of investors, leading to market frictions in trading activity along a geographical line. Moreover, we explore which firms and investor groups tend to be most affected.

The remainder of this paper is organized as follows. Section two discusses related research and develops our hypotheses. Section three describes sample characteristics. Section four contains the event study and explores alternative interpretations of our findings. Section five analyzes determinants of the regional holiday effect. Section six concludes. 


\section{Related Literature and Hypotheses}

By now, there is extensive and robust evidence for local bias on an individual level. ${ }^{1}$ However, research exploring its implications for return and volume patterns is still at the beginning and moreover limited to the US market. Pirinsky and Wang (2006) document an excessive comovement of local stock returns, which they attribute to correlated trading of local residents. Building on investors' consumption smoothing motives, Korniotis and Kumar (2010) argue that stock returns contain a predictable local component. The findings of Hong et al. (2008) suggest that, in the presence of only few local firms competing for investors' money, share prices of spatially close firms are driven up by the excess demand of proximate residents. In a current study based on intra-day data, Shive (2011) exploits large power outages to study the effect of local investor clienteles on pricing efficiency. Her study provides evidence that informed local investors play an important role in information processing and price discovery.

To the best of our knowledge, only two papers focus on the impact of local bias on firmlevel turnover. Loughran and Schultz (2004) show, among other pieces of evidence, that the time zone in which a firm is headquartered triggers intraday trading patterns in its stock. Loughran and Schultz (2005) demonstrate that rural stocks are less liquid than urban stocks, which they attribute to the latter being local and thus visible to more potential investors. They conclude that "much remains to be done on geography and asset pricing" (p. 363). We aim at taking a step in this direction by exploiting holidays which are observed only in some areas of Germany. In our baseline analysis, we focus on All Saints' Day as well as on Epiphany. All Saints' Day, celebrated on November 1 , is legally recognized only in the states of Baden-Wuerttemberg, Bavaria, Northrhine-

\footnotetext{
${ }^{1}$ Heterogeneous findings suggest that both informational and behavioral factors are likely to drive local bias. Studies attributing this behavior to a preference for investing into the familiar, to the pronounced visibility of local stocks or to incorrectly perceived information advantages include e.g. Bailey et al. (2008), Grinblatt and Keloharju (2001), Huberman (2001), Seasholes and Zhu (2010), and Zhu (2003). Papers arguing in favor of superior locally generated information include e.g. Baik et al. (2010), Bodnaruk (2009), Coval and Moskowitz (1999), Coval and Moskowitz (2001), Feng and Seasholes (2004), Ivkovic and Weisbenner (2005), and Massa and Simonov (2006). Moreover, recent studies of Brown et al. (2008), Hong et al. (2004), Hong et al. (2005), Ivkovic and Weisbenner (2007), and Shive (2010) show that local social interaction and neighborhood word-of-mouth effects strongly affect investment decisions. Local bias has been shown to be robust across countries, investor subgroups and sample periods. For the German market, combined findings from e.g. Dorn and Huberman (2005), Dorn et al. (2008), Hau (2001), and this study suggest that, in the overall picture, German investors pose no exception.
} 
Westphalia, Rhineland Palatinate, and Saarland. Epiphany, celebrated on January 6, is a legally recognized holiday only in the states of Baden-Wuerttemberg, Bavaria, and SaxonyAnhalt. There are more regional celebrations in Germany (see the appendix, which is available as supplemental material on the journal's homepage www.revfin.org and from the publisher web site rof.oxfordjournals.org). We partly rely on these holidays in later tests. However, focusing on Epiphany and All Saints' Day yields the most attractive event study properties: It is a yearly event which splits the market in two large disjunct groups with similar characteristics (see section 3 for details).

How holidays in general affect (in particular private) investors' trading behavior is an empirical question. On the one hand, one might expect increased trading activity, as investors may have more time to engage in the stock market. On the other hand, one might expect decreased trading activity, as investors could indulge in vacation activities and thus refrain from participation in the market. Indeed, previous work supports this second line of reasoning. Frieder and Subrahmanyam (2004) show that turnover drops during nationwide holidays. Hong and Yu (2009) provide evidence of aggregate trading activity in international stock markets (including Germany) being lower during summer holiday periods, which they dub a "gone fishin' effect". This seasonality in turnover seems to be caused by both private and professional investors. DellaVigna and Pollet (2009) report that trading activity immediately after earnings announcements made on Fridays is comparatively low, as investors tend to be absent-minded due to the upcoming weekend. With regard to the German setting, the idea of investors being temporarily distracted is backed up by anecdotal evidence from leading papers and news services. ${ }^{2}$ Combined with local bias, this type of limited investor attention makes novel predictions. Specifically, if investors tend to heavily overweight local stocks in their investment decisions, then a large, geographically concentrated subset of holiday-distracted investors might temporar-

\footnotetext{
${ }^{2}$ For instance, Die Welt (May 27, 2005), Financial Times Deutschland (June 12, 2009), Tagesspiegel (June 12, 2009), Stuttgarter Zeitung (May 8, 2007; May 24, 2008), DPA (May 25, 2001), and Dow Jones (June 1, 2007) all report that many investors, both private and professional, stay out of the market on regional holidays and corresponding bridge days. Other articles indirectly point to (primarily retail) investor distraction. For example, Frankfurter Rundschau (October 30, 2004) and Die Welt (November 2, 2004) report that non-holiday states profit from increased holiday tourism. AHGZ (May 12, 2007), a magazine for the hotel and catering sector, states that retail sales volume is higher around regional holidays. Spiegel Online (June 14, 2006) and $d d p$ (June 8, 2009) point to the danger of traffic jams due to the large number of people on a short holiday. Sueddeutsche Zeitung (October 31, 2000) writes about massive obstructions of traffic near graveyards on All Saints' Day, on which it is custom to honor the deceased.
} 
ily change the cross-section of stock turnover:

Hypothesis 1: Due to local bias, trading activity during regional holidays will be significantly lower for firms in holiday regions.

This hypothesis is consistent with the trading volume implications of the habitat-based model of comovement in Barberis et al. (2005). Similarly, in the model of Merton (1987), investors are aware only of a subset of the stock universe. Consequently, the demand for each stock depends on its shadow cost of information. In equilibrium, firms recognized by less investors, will, all else equal, have fewer shareholders taking relatively large positions. It seems plausible to assume that investor recognition of a firm is negatively correlated with geographical distance. We thus expect the impact of local investors to be particularly strong for firms which are hardly visible to remote investors:

Hypothesis 2: The negative turnover shock will be more pronounced for those local firms which are less recognized by non-local investors.

We also explore whether there are differences across investor types, which empirical findings assess to be likely. The aforementioned evidence of limited stock market participation during holidays appears to hold particularly true for private investors. At the same time, retail stock ownership tends to be more exposed to local bias than institutional stock holdings (e.g. Grinblatt and Keloharju (2001)). Small firms have been shown to be investment habitats of retail investors (e.g. Dorn et al. (2008), Kumar and Lee (2006)), whose local bias is particularly concentrated in these stocks (e.g. Zhu (2003)). Thus, traces of retail investor behavior in firm-level turnover should be most easily detected in small stocks. Combined with the observation of Goetzmann and Kumar (2008) that those investors who trade excessively are particularly locally biased, the rich set of findings suggests:

Hypothesis 3: The negative turnover shock in smaller firms will be disproportionately caused by individual investors. 


\section{Sample Characteristics}

We follow the consensus in the literature on local bias and use a firm's headquarter as a proxy for its location. Our initial sample consists of the common stocks of all firms headquartered in Germany which have been listed on a German stock exchange at some point between June 13, 1988 and January 15, 2009. ${ }^{3}$ The lower bound is determined by the availability of the daily number of shares traded. The upper bound is meant to maximize the sample size by the inclusion of Epiphany (January 6) in 2009. The data is then subjected to a three-stage screening process. ${ }^{4}$ This leaves a final sample of 792 stocks, for which the appendix (available on the web as supplemental material) provides descriptive statistics at a weekly frequency. The mean (median) firm is in our sample for 556 (515) weeks, has an average market capitalization of 1,148 (123) million Euro, and has a weekly turnover of $1.42 \%(0.93 \%)$. There is large cross-sectional and considerable time-series variation in turnover, which again motivates the exploration of local bias as a potential driver of firm-level trading activity.

\section{Please insert figure 1 and table 1 about here}

Table 1 shows summary statistics for event study samples. Several findings highlight advantages of the German setting. First, both the treatment (holiday) and the control (non-holiday) groups form large portfolios. Second, their composition does not seem to differ much. For example, median firms have about the same market capitalization and comparable average stock returns. Industry concentration, as computed from Herfindahl

\footnotetext{
${ }^{3}$ See the appendix, which is available on the web as supplemental material, for an overview of all data sets used in this study. For the holidays analyzed here, the Frankfurt stock exchange has been open over the whole sample period, while stock trading at the regional exchanges in Germany started in 2000. This is unlikely to influence our results for three reasons. First, for all sample stocks, the primary exchange from which Datastream obtains its default prices turns out to be the Frankfurt stock exchange. Second, inferences remain unchanged if we restrict our analysis to those stocks which are exclusively traded on the Frankfurt stock exchange. Third, results are robust across time. In particular, they also hold for the subperiod 2000-2009 (see sections 4.2 and 4.3 for details).

${ }^{4}$ First, adjusted and unadjusted daily closing prices, market capitalization, book values, the number of daily shares traded, the number of total shares outstanding, adjustment factors as well as industry membership have to be available via Datastream. Second, we conduct the tests suggested by Ince and Porter (2006). Third, to assure that our analysis is not contaminated by very small and illiquid stocks, we exclude securities if their mean market capitalization is less than 10 million Euro or if the 5th percentile of their unadjusted prices is less than 1 Euro. The main results do not change if we use the sample after step two, which contains 1,071 stocks.
} 
indices based on Datastream Level 2 industry classification, is very similar. The appendix shows that also industry composition appears broadly comparable. Similar findings apply to the fraction of large firm observations. Third, the time-series properties of local turnover indices show a remarkably similar behavior, even in the tails of the distribution. Fourth, an eyeball analysis of figure 1, which shows the geographic distribution of sample firms, reveals that firm location in Germany tends to be less concentrated than in the predominantly used US samples (e.g. Ivkovic and Weisbenner (2005)). Fifth, not only firm-level variables, but also individual investors' characteristics seem comparable. This is suggested by calculations based on data of the German SAVE study ${ }^{5}$, a comprehensive panel survey designed to provide representative information on the financial situation and relevant socio-psychological traits of German households. For example, households' propensity to participate in the stock market, investors' risk taking behavior and economic expectations, their financial literacy and use of financial advice, or the influence of social contacts on financial decision-making is similar in control and treatment groups.

With regard to typical US samples of previous local bias studies, Seasholes and Zhu (2010) highlight a cross-sectional geographic sampling error, which they argue to potentially lead to incorrect conclusions. Taken together, the German setting seems to suffer less from this selection bias. Instead, portfolios are broadly diversified, homogeneous in several dimensions and thus seem particularly suitable for the following natural experiment.

\section{Event Study}

\subsection{METHODS AND BASELINE RESULTS}

In order to quantify the impact of localized trading, one needs to define a measure of trading activity. We focus on firm turnover as "turnover yields the sharpest empirical implications and is the most natural measure" (Lo and Wang (2000), p. 12). As turnover is naturally skewed, we use its natural logarithm in the following calculations. In the regression setting targeted at testing hypothesis 1 , the dependent variable $T O_{i, t}$ is the daily turnover of firm i on a regional holiday at time t. We consider each year from 1988

\footnotetext{
${ }^{5}$ See the appendix for a detailed analysis. For an overview of the SAVE study, see Boersch-Supan et al. (2009).
} 
to 2009 in which the holiday falls on a trading day. For All Saints' Day (Epiphany), this results in $16(14)$ years with a total of $6,485(5,657)$ observations.

During regional holidays, market turnover in general tends to be lower. The average daily turnover of a value-weighted (equal-weighted) turnover index during the whole sample period is $0.42 \%(0.20 \%)$. On Epiphany, these numbers decrease to $0.36 \%$ (0.14\%), on All Saints' Day to $0.29 \%$ (0.13\%). However, we are not interested in changes in trading activity per se, but in potential cross-sectional differences between holiday and non-holiday firms. Thus, the independent variable of interest is the holiday region dummy $H_{o l} l_{i, t}$ that equals one if a firm's headquarter is located in a holiday region and zero otherwise. The null hypothesis is that the dummy should not have any significance.

To isolate the holiday effect, it is essential to control for the expected level $E\left[T O_{i, t}\right]$ of turnover. To assure robustness, we rely on two models widely employed in previous research. Model 1 accounts for firm-specific average turnover in the pre-event period (e.g. Chae (2005)). In the baseline analysis, the expected firm turnover is calculated as the natural logarithm of the average turnover over t-20 to t-2. Model 2 controls for both market-related and firm-specific volume by adopting a "turnover market model" (e.g. Tkac (1999)). To this end, for t-60 to t-2, turnover for each firm is regressed on a marketwide, value-weighted turnover index $T O_{m, t}$. Using the coefficients from the time-series regression, expected turnover is then given by

$$
E\left[T O_{i, t}\right]=\widehat{\alpha}_{i}+\widehat{\beta}_{i} T O_{m, t}
$$

As current firm-level turnover might be related to current stock return (e.g. Chordia et al. (2007)), we include two control variables. Ret $_{+, i, t}$ represents the event day stock return if positive and zero otherwise. ${ }^{6}$ Ret $_{-, i, t}$ is defined analogously. This distinction is motivated by possible asymmetric effects caused by short-selling constraints or the disposition effect, which have been shown to affect localized trading (e.g. Grinblatt and Keloharju (2001)). It has also been documented that turnover is influenced by lagged stock returns (e.g. Statman et al. (2006), Glaser and Weber (2009)). This effect should be captured at least partly by our measures of expected turnover. To more fully control for recent past returns,

\footnotetext{
${ }^{6}$ However, our results do not change if we only include the lagged return or if we do not add return-related control variables at all. Moreover, as shown in section 4.2, inferences are the same when including interaction terms to allow for a different impact of returns on holiday firm turnover.
} 
we include two analogous variables $\left(\operatorname{Ret}_{+, i, t-1}\right.$ and $\left.\operatorname{Ret}_{-, i, t-1}\right)$ for the pre-event day return. The return controls might also be regarded as crude proxies for news or rumors, which could affect turnover. In section 4.3, we comprehensively test for differences in information release between holiday and non-holiday firms.

In our basic regression setting, we employ a Fama-MacBeth approach, combined with the method of Newey and West (1987). We implement the following cross-sectional model in each year and use the resulting time-series of coefficients to assess their significance:

$$
T O_{i, t}=\beta_{0, t}+\beta_{1, t} E\left[T O_{i, t}\right]+\sum_{k=2}^{5} \beta_{k, t} \text { ReturnControl }_{k, i, t}+\beta_{6, t} \text { Hol }_{i, t}+\epsilon_{i, t}
$$

Table 2 shows the findings for the Epiphany sample and the All Saints' Day sample, respectively. Displayed are results from three regression specifications, which differ in the dependent variable. The baseline regression uses firm-specific turnover at the day of the holiday $\left(T O_{i, t}\right)$, the others use the day preceding and following the holiday, respectively.

\section{Please insert table 2 about here}

The holiday region dummy attains a highly negative coefficient in all specifications. For both the Epiphany and the All Saints' Day sample, and for both models of expected turnover, the coefficient is strongly significant at the one percent level. The upper bounds of the $95 \%$ confidence intervals are all well below zero. Moreover, from an economic perspective, the effect is quite large: The pure holiday-induced abnormal drop in volume ranges from roughly $10 \%$ to slightly over $20 \%$. Additionally, results are robust across time: In the Epiphany sample, the holiday region dummy is negative in each year; in the All Saints' Day sample, it attains a negative coefficient in about $80 \%$ of the observations. Finally, the holiday effect can, for the most part, only be identified at the day of the holiday itself. On the day before the holiday, there is no negative shock in trading activity; on the day after, there is some evidence, which, however, is much weaker than on the date of the holiday itself. ${ }^{7}$ In sum, the findings so far support hypothesis 1.

\footnotetext{
${ }^{7}$ As unreported findings suggest, the effect on the day after the holiday might at least partly be attributable to the impact of bridge days as well as the end of Christmas holidays, which varies both across time and states, respectively. This seems also consistent with the anecdotal evidence given in footnote 2 .
} 


\subsection{ROBUSTNESS CHECKS}

The main results from a variety of sensitivity tests are summarized in table 3 .

\section{Please insert table 3 about here}

Our test specification might be misspecified in the sense that it may lead to a spurious positive factor loading on the holiday region dummy on average, irrespective of an actual holiday event. We therefore implement a "placebo treatment": For each model specification and each holiday sample, we randomly select 500 days (excluding the period from $\mathrm{t}-1$ to $\mathrm{t}+1$, where $\mathrm{t}$ denotes the holiday) and, for each of these pseudo events, run the regression as given in Equation (2). Mean and median factor loadings on the holiday region dummy are given in panel A. In all specifications, they are virtually zero.

There is arguably some element of arbitrariness in the length of the pre-event period in both models of expected turnover. Therefore, we experimented with intervals from 10 to 100 trading days. Panel B verifies that inferences remain the same.

It might be possible that the importance of the return controls varies between holiday and non-holiday firms. We thus interact all return variables from the baseline regression with the regional holiday dummy. It turns out that none of them is significant. Panel $\mathrm{C}$ shows that the importance of the holiday region dummy remains unaffected.

One might be concerned that the results could partially be driven by a disproportionate number of holiday firms whose stocks are not traded at the event day. Our findings might then not reflect a broader phenomenon, but rather be attributable to outliers. We thus repeat the analysis discarding all stocks with zero trading volume. However, as shown in panel D, this exercise rather strengthens our results.

Panel E shows results when using raw (instead of logarithmized) turnover. In all specifications, the holiday effect is significant at the $1 \%$ level. Moreover, it keeps its economic significance. For the mean (median) firm the results indicate a pure regional holidayinduced drop in daily trading volume of roughly 200,000 (more than 20,000) Euro. 
Residuals of a given firm might be correlated across years, potentially leading to biased standard errors. We thus follow a suggestion of Petersen (2009) by pooling all firms with non-zero turnover, adding year dummies and clustering standard errors by firm. As shown in panel $\mathrm{F}$, findings are robust to this alternative econometric specification.

Legally recognized regional holidays are observed on a state level. Thus, our interpretation rests on the idea of states being an appropriate classification of the preferred investment habitats of local investors. While similar concepts have been proven fruitful in US studies (e.g. Hong et al. (2008), Korniotis and Kumar (2010)), it is clearly only a noisy proxy. Note, though, that this works against detecting a regional holiday effect: If local investors tilted their trading towards stocks of local firms irrespective of state borders, then it would be hard to identify differences in trading activity between two neighboring states. In an attempt to use a classification scheme with a more pronounced socio-economic background, we repeat our analysis building on metropolitan areas as defined by the Conference of Ministers for Spatial Planning. ${ }^{8}$ Some areas span more than one state, whereas some states contain more than one metropolitan region. Panel G verifies that the coefficient is sporadically estimated even marginally more precisely, possibly pointing to the true impact of localized trading being stronger than reported.

We also study turnover shocks on Corpus Christi as the third legally recognized regional holiday. It is celebrated in the states of Baden-Wuerttemberg, Bavaria, Hesse, North Rhine-Westphalia, Rhineland-Palatinate and Saarland, at the Thursday 60 days after Easter Sunday. Stock market trading on this day started not before 2000, which results in a total of 5,078 firm-level observations distributed over nine yearly observations. Panel H verifies that our findings hold also in this case. The shock in turnover is highly significant, and estimated to be close to $20 \%$. The setting for Corpus Christi is, apart from the shorter sample period and the fixed day of the week, not conceptually different from Epiphany and All Saints' Day. Including all holidays in the remaining tests increases the sample size and ensures that we consider each regional holiday in Germany for which requirements on a meaningful event study are met.

\footnotetext{
${ }^{8}$ This classification identifies eleven metropolitan regions in which roughly $70 \%$ of the German population and $84 \%$ of sample firms are located. http://www.eurometrex.org defines these areas as "larger centres of economic and social life" containing "core business, cultural and governmental functions". We only consider areas clearly belonging either to a holiday or a non-holiday region. This leaves a total of 5,416 (4,350) observations for the All Saints' Day (Epiphany) sample.
} 
However, if our results were representative of a widespread localized trading phenomenon, then we might also detect similar patterns in related scenarios such as Carnival. While there is no official holiday, representative surveys reveal that Carnival is prominent in some (mostly southern and western) regions, but rather unpopular in other (mostly northern and eastern) areas of Germany. ${ }^{9}$ Despite the lack of clear-cut separation between affected and non-affected regions, we run an analogous analysis for Carnival Monday, on which most parades are held. Panel I provides evidence supportive of our line of reasoning.

\subsection{DIFFERENCES IN INFORMATION INTENSITY?}

A key concern to a local bias story is that holiday firms might simply release less information than otherwise comparable non-holiday firms. To the extent that this triggers rebalancing trades or increased differences of opinion, it might partly explain our findings. As an intuitive and rather informal first approach to explore the possibility of such an information effect, we compare the fraction of corporate news released around the holiday. To this end, we rely on firm-specific news stories published by DGAP, a German news agency, from January 2000 to January 2009. These news include time-stamped ad hoc disclosures, by which German firms are forced to publish new value-relevant information immediately. We manually collect these disclosures for each sample firm. The database additionally covers a broad range of other news, such as directors' dealings or business reports. Since data retrieval is labor intensive, we gather these corporate news for half of sample firms, which we randomly select. The following test is based on this subsample.

We create a dummy variable that states for each firm and each day whether corporate news or ad hoc disclosures have been released. Then, for each holiday, and separately for the holiday and the non-holiday sample, we compute the fraction of all news attributable to a short window around the holiday $(t-1$ to $t+1)$. After that, we compute an odds ratio

\footnotetext{
${ }^{9}$ We here rely on survey results published in the magazine "Daheim in Deutschland" (by Reader's Digest), February 2010. Our classification is based on the fraction of individuals stating to actively participate in carnival celebrations. The areas of Hesse, Rhineland Palatinate, Saarland (roughly 30\%), Bavaria (27\%), Baden Württemberg (25\%) and North RhineWestphalia (24\%) serve as a treatment group. The remaining regions have participation rates between $10 \%$ and $19 \%$ and thus serve as a control group. A related classification scheme based on the relative popularity of carnival clubs leads to similar results. Data for this analysis is provided by "Bund Deutscher Karneval", the umbrella organization of several thousand German carnival clubs.
} 
by dividing the percentage obtained for the holiday sample by the percentage obtained for the non-holiday sample. If holiday firms released temporarily less news, we would expect values persistently well below one. However, the odds ratios are 1.05 for Epiphany, 1.02 for All Saint's Day and 0.84 for Corpus Christi, pointing against a widespread drop in news release. As later sections of this study reveal that firm size is an important determinant of the drop in trading activity, we determine whether this might be due to differences in news release. Specifically, we repeat the analysis separately for large and small stocks, split by the median of market capitalization at the beginning of the year. Around Epiphany, there are no marked differences. Around All Saint's Day, small holiday firms appear to release relatively more news than large holiday firms. Around Corpus Christi, this picture partly reverses. In sum, there is no clear pattern.

For deeper insights, we test more rigorously for differences in news arrival from four further perspectives. Specifically, we study cross-sectional shocks with regard to abnormal price movements, with regard to the degree of analyst coverage, with regard to investors' internet search behavior as well as with regard to firms' media exposure. In the following, these tests, whose main results are presented in tables 4 and 5, are described in detail.

\section{Please insert table 4 and table 5 about here}

Firm-specific news are likely to affect the magnitude of abnormal returns. Firm-specific information should manifest itself in an increased importance of the idiosyncratic component of the firm's daily stock return. On the other hand, if there is hardly any new information, then the return should primarily be driven by the stock's exposure to pervasive well-known risk factors. Thus, if there was indeed temporarily less news for the typical holiday firm, we would expect its absolute abnormal return to be considerably lower than during some control period on average. For the typical non-holiday firm, however, there should be no or at least not as much of a difference. A benefit of this approach is that shock variables can be computed continuously, providing data for each firm on each day. This overcomes the problem that official news coverage of a given firm may be sporadic, even though there might be rumors, speculation or private information investors react on. To formalize the cross-sectional prediction as sketched above, we employ the following procedure. First, for each firm and each day, we compute the abnormal stock return. By 
employing both a market model and a Carhart (1997) four factor model, we follow standard event study methodology; due to very similar findings, only the findings from the latter model are reported. The four factor model is based on German data and includes the market, size and value factors in the spirit of Fama and French (1993) and the momentum factor as constructed in Carhart (1997). The appendix provides more detailed information about the construction of the factors. Second, for each firm, we compute the difference between the absolute abnormal return on the day of the holiday $(=\mathrm{t})$ and the average absolute abnormal return in some control period. We here rely on the period from $\mathrm{t}-5$ to $\mathrm{t}+5$ (excluding $\mathrm{t}$ ), but results are not sensitive to this choice. The resulting variable has the interpretation of an unexpected change in the relative importance of idiosyncratic stock return factors. Third, for both the holiday and the non-holiday sample, we rank firms based on this shock variable. We take the cross-sectional median for both samples to get an estimate of the shock for the typical firm. ${ }^{10}$ Fourth, we compute the cross-sectional difference between the median shock for the holiday sample and the median shock for the non-holiday sample. A news-based explanation of our findings would predict values significantly below zero, as the shock in the relative importance of firm-specific return factors for the typical holiday (non-holiday) firm should be more (less) negative. We repeat the procedure in each year. Finally, a bootstrap approach ${ }^{11}$ is used to test whether the average of the resulting time series of differences is statistically distinguishable from zero. However, panel A of table 4, which reports results for the Epiphany, All Saints' Day as well as Corpus Christi sample, shows that this not the case. The only slightly significant event is on the day of Epiphany, where, from an economic perspective, the resulting return difference appears small. For all other holidays, differences are very close to zero and insignificant, implying that in most cases shocks in abnormal returns do not differ much between holiday and non-holiday firms. Pooling observations does not lead to different

\footnotetext{
${ }^{10}$ The appendix provides more details about the distribution of shock variables. It verifies that findings are qualitatively similar when relying on the mean (instead of the median) of the winsorized cross-section. It also shows that extreme return events are only slightly more frequent for non-holiday firms.

${ }^{11}$ The comparison of shock variables results in a holiday-specific time series of differences between holiday and nonholiday firms. We use this data to simulate 10,000 pseudo time-series of the same length as the original sample by randomly drawing values with replacement. Averaging values separately for each pseudo time-series yields 10,000 pseudo estimates of the difference in median shock variables. Finally, we assess whether the value obtained from the averaged original time-series is reliably negative by computing the fraction of simulated estimates that take on values below zero. For a discussion of simulations in event studies, see e.g. Lyon et al. (1999).
} 
conclusions. Moreover, there are no persistent differences for large and small stocks, again split by the median of market value.

Our second test is inspired by Da et al. (2011) and based on cross-sectional shocks in search frequencies for firm names in Google. The application "Google Insights for Search" allows to construct standardized time-series of terms entered in the internet search engine. Data is available on a daily basis from January 2004 on. Computing shocks in search volume might be regarded as a possibility to quantify unexpected changes in revealed (and thus direct) focus to individual firms, induced by some external stimulus. In this sense, changes in the query frequency of a firm name ${ }^{12}$ appear a promising way of capturing shocks in the arrival of firm-specific news or rumors. For example, Da et al. (2011) report a positive correlation between search volume shocks and traditional proxies for information release, such as extreme returns and news stories. The authors show that internet search volume even often leads alternative measures of news arrival. We thus construct a measure of unexpected search behavior for each firm based on daily data. It is defined as the difference between the search frequency during the holiday $(=\mathrm{t})$ minus the average frequency over t-10 to t-2, divided by the standard deviation in this pre-event period. We then pool observations and regress the shock variables on a holiday region dummy in addition to controls for years and industries. We do so for the sample of all firms, of large firms, and of small firms. Panel B of table 4 shows that all holiday region dummy coefficients are insignificant, both separately and jointly, pointing against a news-based story.

Our third analysis focuses on the large effort of analysts in collecting, processing and disseminating information (e.g. Womack (1996)). We are interested in whether aggregated analyst coverage during regional holidays differs from coverage in a nearby benchmark period. Specifically, we concentrate on the number of daily analyst recommendations issued, and determine whether the fraction holiday firms account for is exceptionally low during

\footnotetext{
${ }^{12}$ One might be concerned about the use of firm names. They might not be unambiguous and a few of them clearly have multiple meanings. However, this seems unlikely to drive our main results. First, we study differences between two large samples with several hundred firm names. Thus, any potential inaccuracies and inconsistencies are likely to cancel out. Second, we are interested in shocks of search frequencies, i.e. we control for the expected level of queries. Third, "Google Insights for Search" additionally provides a top search list with the terms most closely related to the original search. In an attempt to manually cleanse the data, we used that information to exclude those firms that seemed most likely to distort the analysis. Inferences remained unchanged. The alternative of relying on security identification numbers instead of firm names turned out to be unproductive as search frequencies tend to be much lower, resulting in many missing values.
} 
the holiday. This is what a news-based explanation of our findings would arguably predict. To test this hypothesis, we match our sample with the I/B/E/S analyst buy/hold/sellrecommendations database. This results in a total of 51,497 stock recommendations of 196 brokers, which cover more than $80 \%$ of the sample firms. For the eleven day period centered around the holiday $(\mathrm{t}-5$ to $\mathrm{t}+5)$, we then determine which fraction of all recommendations issued on this day is attributable to holiday firms. The length of this benchmark period is meant to account for the seasonality in earnings reports, but the qualitative nature of our findings is robust to alternative control windows. We average values for t. Values for the benchmark period (excluding t) are pooled to give rise to an empirical benchmark distribution of relative analyst coverage for holiday firms. Relying on the percentiles of this distribution, we are able to detect whether analyst information transmission for holiday firms exhibits a negative shock. We distinguish between a value-weighted analysis, in which multiple recommendations made for the same firm on the same day are considered as multiple observations, and an equal-weighted analysis, in which we regard such a scenario as a single observation. The latter tends to give more weight to small firms, which less often receive several recommendations at the same day. As a sensitivity check, we repeat the analysis now focusing on the review date, i.e. the most recent date that an estimate is confirmed by an analyst to I/B/E/S as accurate. Panel C of table 4 shows the fraction of total analyst coverage on the event day. Percentiles are given in parentheses. A higher percentile indicates that holiday firm recommendations account for a larger fraction of the total number of recommendations issued. In all specifications, coverage does not seem to decrease for firms located in holiday regions. Judging from the percentiles of the distribution, the holiday rather appears like an average day of the benchmark period. ${ }^{13}$ Moreover, the value-weighted and the equal-weighted analysis show a similar picture, suggesting there are no marked differences between large and small firms.

As a final test, we study shocks in media coverage in three leading German daily business newspapers, which are published nation-wide. ${ }^{14}$ The comprehensive database, for which

\footnotetext{
${ }^{13}$ One might be concerned about noise in the data. Indeed, a similar bootstrapping approach as outlined in footnote 11 reveals that the dispersion of simulated outcomes is quite substantial. However, even the lower bound of the $99 \%$ confidence interval does not touch the 10th percentile of the benchmark distribution, which contradicts an information-based story.

${ }^{14}$ IVW, a German auditing institution that provides data on the distribution of media products, reports that Sueddeutsche Zeitung had the second highest circulation among nationwide published daily papers over the period 2000 to 2008 . It ranks
} 
panel A of table 5 gives more details, is based on daily data from January 1, 2000 on and comprises Financial Times Deutschland, Handelsblatt and Sueddeutsche Zeitung. Searching factiva and genios, articles about each firm for each day and in each paper are manually collected. ${ }^{15}$ This results in a total of 126,125 news stories covering almost $94 \%$ of our sample firms. Again, we distinguish between a value-weighted and an equal-weighted analysis. The latter relies on a dummy variable that simply states whether a firm has received press coverage on a given day. The former individually counts each article. It thus takes on values greater than one if there are several firm news stories in the same paper, or if several papers cover the firm. In doing so, it tends to give more weight to blue chips and big news. For further insights, we additionally split firms into large and small stocks, as before. Across all specifications, there is considerable variation in daily media coverage. For instance, on a given day, the fraction of news stories attributable to firms that didn't make the news the day before, is $63 \%$ (52\%) for the equal-weighted (value-weighted) analysis on average. Focussing on small firms yields even $91 \%$ (90\%).

Panel B shows results from a test similar to the one used for analyst coverage. We analyze whether aggregated media coverage for holiday firms is abnormally low around the holiday. We consider both the event day and the following day, as information becoming public at $t$ can not be published by newspapers before $t+1$. To assess statistical significance, we calculate the percentage of total media coverage attributable to holiday firms for each day of the year. ${ }^{16}$ We then analyze the fraction of press coverage around the holiday relative to the whole empirical distribution, which does not exhibit strong seasonal patterns. The analysis produces mixed results. Around All Saints' Day, media coverage for holiday firms

first if one excludes the popular press. Among the daily newspapers with a strong focus on business and economics, Handelsblatt and Financial Times Deutschland rank first and second. In the fourth quarter of 2008, the three newspapers had a combined circulation of more than 800,000 copies per day.

\footnotetext{
${ }^{15}$ Similarly as in Tetlock et al. (2008), we thereby require the article to mention at least twice the name or security identification number of the firm. This procedure aims at reducing noise and identifying relevant firm-specific articles. Coverage for Financial Times Deutschland starts on January 1, 2001.

${ }^{16}$ We thereby account for the fact that not all newspapers are published at each day of the year: At Corpus Christi, Handelsblatt and Sueddeutsche Zeitung are not distributed. At Epiphany, Sueddeutsche Zeitung is not published. This is unlikely to materially influence our analysis. First, for the more important date t+1, all newspapers are available. Findings are similar as on date t. Second, the results from the equally- and from the value-weighted analysis are similar in general. This suggests that relevant information is, for the most part, picked up by each of these leading newspapers so that partly relying on a subset of them does not change the qualitative nature of the results. This line of reasoning is also supported by the highly significant correlations in daily firm-level media coverage as shown in panel A of table 5 .
} 
is indeed significantly lower, which, in line with findings from the test on corporate news releases, appears to be driven by larger firms. However, there is no similar evidence for any of the other holidays. In fact, press coverage is sometimes even higher than on average. In the overall picture, results point against a strong general drop in media exposure for both large and small holiday firms. To gain more insight, we implement a more formal regression approach. We create the dummy $N e w s_{i, t}$ which indicates for each firm i on each day of the eleven trading days period centered around the regional holiday whether a news article was published. ${ }^{17}$ We then pool the observations and run the following probit regression separately for Epiphany, All Saints' Day and Corpus Christi:

$$
N E W S_{i, t}=\beta_{0}+\beta_{1} \text { EventDummy }+\beta_{2} \text { HolidayRegionDummy }+\beta_{3} \text { InteractionTerm }+ \text { YearDummies }+\epsilon_{i, t}
$$

The event dummy indicates the holiday within the event period. We also run analogous regressions for the days preceding and following the holiday. Of interest is the interaction effect between the event dummy and the holiday region dummy. If the volume shock was a result of systematic cross-sectional differences in press coverage, then it should consistently attain a significantly negative sign. Panel $\mathrm{C}$ of table 5 reports results from the nine probit regressions. Magnitude and significance of the interaction effect are assessed as suggested by Ai and Norton (2003). Again, the only significant results are found for the All Saints' Day sample. Thus, the findings at best sporadically point to differences in information release picked up by the press.

We finally incorporate additional control variables in our pooled regression approach as outlined in section 4.2. For data availability reasons, we focus on the period from 2000 to 2009, and add a set of dummies to control for the effect of media coverage and ad hoc disclosures on any day between $t-5$ and $t+5$. Panel $\mathrm{D}$ of table 5 reveals that the regional holiday effect keeps its significance, both from an statistical and an economic point of view. Modifying the analysis by focussing only on those stocks for which we have additional information about the release of other corporate news yields similar results.

Taken together, the combined findings from all tests in this section provide the following

\footnotetext{
${ }^{17}$ We choose this binary approach to reduce the overcounting of news about the same subject from multiple sources. However, an analysis focussing on the actual number of news produces very similar results. The eleven day period is largely representative for the media coverage in the whole year.
} 
picture: First, we cannot dismiss the hypothesis of lower information intensity for holiday firms as there is minor evidence of differences in news release. Their lack of robustness and small magnitude, however, suggest they are unlikely to fully explain the economically substantial and pervasive drop in trading volume for holiday firms. The evidence points against persistent disparities between small and large firms. Second, controlling for potential differences in news arrival to the extent possible, our results remain qualitatively unchanged. Third, these findings strongly confirm hypothesis 1.

\section{Determinants of the Regional Holiday Effect}

Firm characteristics What factors drive the cross-sectional heterogeneity in negative turnover shocks? To answer this question, we first construct a firm-specific measure of abnormal turnover, defined as actual (logarithmized) turnover during the holiday minus the average turnover during t-20 to t-2. For robustness reasons, we then run pooled regressions separately for each of the three holiday samples as well as for two sample periods.

Hypothesis 2, inspired by the model of Merton (1987), posits that the turnover shock should be particularly strong if a firm is visible primarily to local investors. Merton argues that investor recognition is a function of the shadow cost of information, which, in his model, depends on idiosyncratic risk, relative market size and the completeness of the shareholder base. We thus use the logarithm of a firm's market capitalization, as measured at the end of the preceding year, and a firm's idiosyncratic risk as independent variables. Idiosyncratic risk is defined as the standard deviation of the residual obtained by fitting a Carhart (1997) four factor model (as described in section 4.3) to the daily return timeseries from t-180 to t- 6 .

Market capitalization is strongly negatively related to the total number of shareholders (e.g. Grullon et al. (2004)) and positively related to the fraction of local investors (e.g. Zhu (2003)). Consequently, we expect a smaller drop in volume for larger firms, which implies a positive coefficient for firm size. Idiosyncratic risk, on the other hand, increases the shadow cost of information. Local investors are commonly thought to possess (actual or perceived) informational advantages. Thus, local clienteles should account for a relatively large proportion in the trading of stocks with high idiosyncratic risk, which should go along 
with a more pronounced negative volume shock during regional holidays. Consequently, a negative coefficient is expected.

In addition, we employ with residual media coverage a third proxy, which is orthogonal to size and available for the years 2001 to 2009. The residual is obtained from yearly cross-sectional regressions of the number of firm-specific press articles in the previous year on its lagged average market size, turnover and absolute return as well as on a set of control variables for industry and DAX30 membership. Press articles are taken from the comprehensive media coverage database described in section 4.3. Residual coverage is designed to proxy for the unexpected high or low weight the media attaches to a certain firm. Given the importance of leading business newspapers in disseminating information to a broad audience, residual media coverage is an intuitive measure of firm visibility. Consequently, we expect a positive coefficient.

Previous research and our baseline analysis highlighted the importance of current returns for current turnover. We thus include the same two return-based variables in the regression. To control for additional effects induced by medium-term return continuation, we consider the loading on the momentum factor $(W M L)$, obtained from a regression of stock returns on the Carhart (1997) four factor model. The loadings on the market as well as value factor $(R M R F, H M L)$ are considered as proxies for systematic risk (e.g. Chordia et al. (2007)). The intercept from this regression (Alpha) is included as it has been argued to contain a premium related to liquidity or heterogeneous information (e.g. Lo and Wang (2000)). Moreover, we include a rural dummy for firms located outside a metropolitan region. The "only game in town effect" (Hong et al. (2008)) suggests a negative coefficient. Inspired by e.g. Seasholes and Wu (2007), a 52 week high dummy for stocks whose price has exceeded this bound in the previous week is considered. Finally, we include a set of industry dummies.

For each holiday, table 6 displays univariate and multivariate results for the whole sample period. We report coefficients for the subperiod 2001 to 2009 separately. These coefficients additionally include residual media coverage and controls for the availability of press articles as well as ad hoc disclosures around the event date (see also section 4.3).

\section{Please insert table 6 about here}


The findings are broadly consistent with our expectations. Investor recognition seems an important driver of the turnover shock. All proxies consistently attain the predicted sign and, with the exception of idiosyncratic risk, are persistently statistically significant. The effect of market capitalization is clearly the strongest, but residual media coverage has an incremental effect. The magnitude of the results is also of economic importance: As a rough estimate, for example, a one standard deviation change in firm size has a similar impact as a one standard deviation change in stock return. The current absolute return is highly significant. The dummies for rural firms and the 52 week high attain coefficients as predicted, but their importance is not robust. The other controls seem to play only a minor role. In sum, hypothesis 2 can broadly be confirmed. The regional holiday effect is considerably stronger for firms less visible to non-local investors.

Investor characteristics In this section, we aim at gaining additional insights from the daily tracking records of roughly 3,000 retail clients of a German online broker from January 1997 to April 2001. Comprehensive information about the sample, such as details about the construction of portfolio holdings, is given in Glaser and Weber (2009) and Glaser and Weber (2007). Sample investors account for a total of 316,134 stock transactions, out of which 136,125 take place in 965 German firms. As the latter represent roughly $50 \%$ of all transactions traceable via Datastream, investors seem to exhibit a strong home bias. Panels A to C of table 7 provide descriptive statistics, which show that sample investors trade frequently. The mean (median) number of transactions in German firms is $47(22)$, leading to a total sample trading volume of more than 750 million Euro.

\section{Please insert table 7 about here}

For the purpose of our analysis, the data set has two advantages. First, the broker does not offer investment advice. Therefore, trading decisions are not affected by bank recommendations. Second, online broker investor trading on regional holidays is not restricted in any way. Results suggestive of localized trading might thus be considered conservative in the sense that other investors might face higher obstacles, such as finding an open bank office. ${ }^{18}$ A disadvantage of the sample is that investor location is not provided. Given this

\footnotetext{
${ }^{18}$ Note again that this does not have cross-sectional implications for abnormal stock turnover unless local investors' trading decisions systematically deviate from remote investors' buys and sells.
} 
limitation, exploring to what extent investors exhibit local bias (in addition to home bias), is not a straightforward exercise. We thus start our analysis with the reasonable assumption that a disproportionate fraction of the broker's clients live in the region in which the broker is headquartered. Locally biased investors should then have a strong preference for firms also located in the affected metropolitan area. ${ }^{19}$ To test this, we compute a sample investor preference measure as the difference between a firm's brokerage weight and its weight in the market portfolio of German stocks. The firm's brokerage weight is defined as the total volume invested in the firm's stock by the broker's clients divided by the total volume the clients invest in all German stocks at the time. We do so at the beginning of each month and for each firm traded at least once on any day by any sample investor. We average stock-specific time-series to obtain an average estimate, based on which we sort firms in one of three portfolios of equal size: "Low preference", "medium preference" and "high preference". Then, for each of these portfolios, we determine the fraction of firms located in the same metropolitan area as the online broker itself. As the metropolitan area turns out to be large, there is sufficient level of diversification. Consequently, if sample investors were not locally biased, we would expect the fraction of firms located near the online broker to be similar across preference portfolios. However, panel D shows that this is not what we find. The fraction of the "medium preference" portfolio is standardized to 1 . Therefore, the value 1.29 for the "high preference" portfolio implies that there are close to $30 \%$ more local firms than would be expected on average by chance.

Having verified the existence of at least some local bias, we turn to a test suggested by hypothesis 1: Holiday trading activity should decrease in local bias. We label each firm located in the broker's metropolitan area a "low preference", "medium preference" or "high preference" firm. Then, we compute the daily fraction of aggregate sample investor trading volume that is attributable to each of these portfolios, leading to an empirical benchmark distribution for portfolio-specific relative trading activity. Similarly as in previous tests, we determine the percentile of the distribution that is observable during the day of the regional holiday. ${ }^{20}$ Hypothesis 1 predicts that these percentiles should decrease

\footnotetext{
${ }^{19}$ To sharpen the analysis, we focus on the metropolitan area classification as outlined in section 4.2. Results are similar when we make use of states instead. Moreover, to mitigate the effect of a few extremely large trades that could materially affect the analysis, we winsorize investor transactions at the $99.9 \%$ level in all following tests.

${ }^{20}$ To sharpen the analysis, we focus on the holiday that most clearly separates the broker's metropolitan area as a holiday region from as many other metropolitan areas as possible.
} 
in local investors' preference - firms with a high degree of local bias should exhibit a more pronounced shock in relative trading volume. Panel E shows that this is indeed what we find. The "high preference portfolio" temporarily exhibits the lowest trading activity, no matter if one focuses on the total Euro volume traded, the number of transactions conducted or the number of investors trading.

We now turn to hypothesis 3 , which posits that the turnover drop in small stocks is disproportionately caused by private investors. To this end, we aggregate data and conduct tests based on shocks in a measure called Ratio $_{i, t}$. For holiday i, it is computed as the overall fraction of daily "holiday firm trading" by online broker investors divided by the fraction of daily "holiday firm trading" by the whole market. The rationale is as follows: As the daily trading volume of the investor sample is positively correlated (0.39) with the daily market trading volume for these firms, it appears justified to use market volume as a benchmark. By focussing on shocks of Ratio $_{i, t}$, one mitigates the problem of lacking information on investor location, as the expected level of trading in each group of stocks is automatically accounted for. To identify shocks, we control for the autoregressive properties of Ratio $_{i, t}$ by employing AR(p)-processes similar to Connolly and Stivers (2003). Shocks are defined as the residual $\epsilon_{i, t}$ from the following regression:

$$
\text { Ratio }_{i, t}=\beta_{i, 0}+\sum_{k=1}^{p} \beta_{i, k} \text { Ratio }_{i, t-k}+\epsilon_{i, t}
$$

$\mathrm{P}$ denotes the maximum lag, up to which each estimated coefficient on each lagged term of Ratio $_{i, t}$ is individually significant, and takes on values between two and five for the specifications described below. $\epsilon_{i, t}$ can thus be interpreted as unexpected daily changes in holiday firm trading of retail investors as compared to the whole market.

To test hypothesis 3 , we compute Ratio $_{i, t}$ separately for the whole sample as well as for small and large stocks, split by the median of market capitalization at the beginning of the year. We do this for each of the three holidays. We then determine the most suitable $\mathrm{AR}(\mathrm{p})$-process for each of the nine specifications and run the regression as given in Equation (4). This results in nine shock time series. Finally, we apply these to the seven holiday observations that take place on a trading day during our retail investor sample period: Epiphany is celebrated four times, All Saints' Day twice and Corpus Christi once. Panel F of table 7 reports the percentiles of the shock variables for each stock sample (all, 
large, small). The results for large stocks and for the whole sample appear like random draws from the distribution. In other words, there are no systematic differences between individual investors and the overall market. However, focussing explicitly on smaller firms, a clear pattern emerges: Online broker investors' trading activity consistently exhibits negative shocks at the day of the holiday when benchmarked against the whole market. The value of the shock variable is well below its median for every single observation. Assuming independence, the likelihood of observing this result by chance is below $1 \%$. In other words, the findings are consistent with hypothesis 3.

\section{Conclusion}

We run a series of natural experiments which collectively suggest that local bias leaves discernible traces in the cross-section of firm-level trading activity. The German setting allows us to compare abnormal turnover in several treatment groups, i.e. hundreds of firms in holiday regions, with turnover in control groups, i.e. in many ways very similar firms in non-holiday regions. Ceteris paribus, firms in holiday regions are remarkably less traded. This finding is mostly confined to the day of the holiday itself, statistically significant, economically meaningful, robust, and does not appear to be completely driven by differences in information release. Instead, consistent with a local bias explanation and the model of Merton (1987), it is particularly strong for firms less recognized by non-local investors. Moreover, in line with predictions of previous research, the turnover shock in smaller stocks seems to be disproportionately caused by individual investors.

The basic message of this study is a simple one: Local investor clienteles are strong and pervasive enough to generate frictions segmenting the stock market along a geographical line. Our analysis also contributes to research on determinants of firm-level trading volume by establishing cross-sectional regularities related to firm location, firm visibility, and investor clienteles. Moreover, by uncovering a link between the potentially powerful role of local investors, investor distraction, and the cross-section of firm turnover, we might provide a new fruitful starting point for the emerging research on the joint dynamics of investor attention, trading volume, and price discovery. 


\section{References}

Ai, C., and E. C. Norton, 2003, "Interaction terms in logit and probit models," Economic Letters, 80, 123-129.

Baik, B., J.-K. Kang, and J.-M. Kim, 2010, "Local institutional investors, information asymmetries, and equity returns," Journal of Financial Economics, 97, 81-106.

Bailey, W., A. Kumar, and D. Ng, 2008, "Foreign investments of U.S. individual investors: Causes and consequences," Management Science, 54, 443-459.

Barberis, N., A. Shleifer, and J. Wurgler, 2005, "Comovement," Journal of Financial Economics, 75, 283-317.

Bodnaruk, A., 2009, "Proximity always matters: Local bias when the set of local companies changes," Review of Finance, 13, 629-656.

Boersch-Supan, A., M. Coppola, L. Essig, A. Eymann, and D. Schunk, 2009, "The German SAVE study - Design and results," MEA Study No. 6.

Brown, J. R., Z. Ivkovic, P. A. Smith, and S. Weisbenner, 2008, "Neighbors matter: Causal community effects and stock market participation," Journal of Finance, 63, 1509-1531.

Carhart, M. M., 1997, "On persistence in mutual fund performance," Journal of Finance, $52,57-82$.

Chae, J., 2005, "Trading volume, information asymmetry, and timing information," Journal of Finance, 60, 413-442.

Chordia, T., S.-W. Huh, and A. Subrahmanyam, 2007, "The cross-section of expected trading activity," Review of Financial Studies, 20, 709-740.

Connolly, R., and C. Stivers, 2003, "Momentum and reversals in equity-index returns during periods of abnormal turnover and return dispersion," Journal of Finance, 58, $1521-1556$.

Coval, J. D., and T. J. Moskowitz, 1999, "Home bias at home: Local equity preference in domestic portfolios," Journal of Finance, 54, 2045-2073.

— , 2001, "The geography of investment: Informed trading and asset prices," Journal of Political Economy, 109, 811-841. 
Da, Z., J. Engelberg, and P. Gao, 2011, "In search of attention," forthcoming Journal of Finance.

DellaVigna, S., and J. M. Pollet, 2009, "Investor inattention and Friday earnings announcements," Journal of Finance, 64, 709-749.

Dorn, D., and G. Huberman, 2005, "Talk and action: What individual investors say and what they do," Review of Finance, 9, 437-481.

Dorn, D., G. Huberman, and P. Sengmueller, 2008, "Correlated trading and returns," Journal of Finance, 63, 885-920.

Fama, E. F., and K. R. French, 1993, "Common risk factors in the returns on stocks and bonds," Journal of Financial Economics, 33, 3-56.

Feng, L., and M. S. Seasholes, 2004, "Correlated trading and location," Journal of Finance, 59, 2117-2144.

Frieder, L., and A. Subrahmanyam, 2004, "On non-secular regularities in trading activity and stock returns," Financial Analysts Journal, 60, 29-34.

Gao, X., and T.-C. Lin, 2010, "Do behavioral needs influence the trading activity of individual investors? Evidence from repeated natural experiments," Unpublished working paper, University of Hong Kong.

Glaser, M., and M. Weber, 2007, "Overconfidence and trading volume," Geneva Risk and Insurance Review, 32, 1-36.

— , 2009, "Which past returns affect trading volume?," Journal of Financial Markets, $12,1-31$.

Goetzmann, W. N., and A. Kumar, 2008, "Equity portfolio diversification," Review of Finance, 12, 433-463.

Grinblatt, M., and M. Keloharju, 2001, "How distance, language, and culture influence stockholdings and trades," Journal of Finance, 56, 1053-1073.

Grullon, G., G. Kanatas, and J. P. Weston, 2004, "Advertising, breadth of ownership, and liquidity," Review of Financial Studies, 17, 439-461. 
Hau, H., 2001, "Location matters: An examination of trading profits," Journal of Finance, 56, 1959-1983.

Hirshleifer, D., S. S. Lim, and S. H. Teoh, 2009, "Driven to distraction: Extraneous events and underreaction to earnings news," Journal of Finance, 64, 2289-2325.

Hong, H., J. D. Kubik, and J. C. Stein, 2004, "Social interaction and stock-market participation," Journal of Finance, 59, 137-163.

— , 2005, "Thy neighbor's portfolio: Word-of-mouth effects in the holdings and trades of money managers," Journal of Finance, 60, 2801-2824.

— , 2008, "The only game in town: Stock-price consequences of local bias," Journal of Financial Economics, 90, 20-37.

Hong, H., and J. Yu, 2009, "Gone fishin': Seasonality in trading activity and asset prices," Journal of Financial Markets, 12, 672-702.

Hou, K., L. Peng, and W. Xiong, 2009, "A tale of two anomalies: The implications of investor attention for price and earnings momentum," Unpublished working paper, Ohio State University, City University of New York, Princeton University.

Huberman, G., 2001, "Familiarity breeds investment," Review of Financial Studies, 14, 659-680.

Ince, O. S., and R. B. Porter, 2006, "Individual equity return data from Thomson Datastream: Handle with care!," Journal of Financial Research, 29, 463-479.

Ivkovic, Z., and S. Weisbenner, 2005, "Local does as local is: Information content of the geography of individual investors' common stock investments," Journal of Finance, 60, 267-306.

— , 2007, "Information diffusion effects in individual investors' common stock purchases: Covet thy neighbors' investment choices," Review of Financial Studies, 20, 13271357.

Korniotis, G. M., and A. Kumar, 2010, "State-level business cycles and local return predictability," Unpublished working paper, University of Miami.

Kumar, A., and C. M. Lee, 2006, "Retail investor sentiment and return comovements," Journal of Finance, 61, 2451-2486. 
Lo, A. W., and J. Wang, 2000, "Trading volume: Definitions, data analysis, and implications of portfolio theory," Review of Financial Studies, 13, 257-300.

Loughran, T., and P. Schultz, 2004, "Weather, stock returns, and the impact of localized trading behavior," Journal of Financial and Quantitative Analysis, 39, 343-364.

— , 2005, "Liquidity: Urban versus rural firms," Journal of Financial Economics, 78, $341-374$.

Lyon, J. D., B. M. Barber, and C.-L. Tsai, 1999, "Improved methods for tests of long-run abnormal stock returns," Journal of Finance, 54, 165-201.

Massa, M., and A. Simonov, 2006, "Hedging, familiarity and portfolio choice," Review of Financial Studies, 19, 633-685.

Merton, R. C., 1987, "A simple model of capital market equilibrium with incomplete information," Journal of Finance, 42, 483-510.

Newey, W. K., and K. D. West, 1987, "A simple, positive semi-definite, heteroskedasticity and autocorrelation consistent covariance matrix," Econometrica, 55, 703-708.

Petersen, M. A., 2009, "Estimating standard errors in finance panel data sets: Comparing approaches," Review of Financial Studies, 22, 435-480.

Pirinsky, C., and Q. Wang, 2006, "Does corporate headquarters location matter for stock returns?," Journal of Finance, 61, 1991-2015.

Seasholes, M. S., and G. Wu, 2007, "Predictable behavior, profits, and attention," Journal of Empirical Finance, 14, 590-610.

Seasholes, M. S., and N. Zhu, 2010, "Individual investors and local bias," Journal of Finance, 65, 1987-2011.

Shive, S. A., 2010, "An epidemic model of investor behavior," Journal of Quantitative and Financial Analysis, 45, 169-198.

—_ 2011, "Local investors, price discovery, and market efficiency," Unpublished working Paper, University of Notre Dame.

Statman, M., S. Thorley, and K. Vorkink, 2006, "Investor overconfidence and trading volume," Review of Financial Studies, 19, 1531-1565. 
Tetlock, P. C., M. Saar-Tsechansky, and S. Macskassy, 2008, "More than words: Quantifying language to measure firms' fundamentals," Journal of Finance, 63, 1437-1467.

Tkac, P. A., 1999, "A trading volume benchmark: Theory and evidence," Journal of Financial and Quantitative Analysis, 34, 89-114.

Womack, K. L., 1996, "Do brokerage analysts' recommendations have investment value?," Journal of Finance, 51, 137-167.

Zhu, N., 2003, "The local bias of individual investors," Unpublished working paper, Yale University. 
Figure 1: Geographic Distribution of Firm Headquarters and of Regional Holidays across Germany

This figure shows the location of firm headquarters across Germany. Headquarters are represented by black circles; additional clusters of headquarters (with more than 20 firms) in a given city are represented by red numbers. These correspond, from west to east, to the cities of Duesseldorf (28 firms), Cologne (36 firms), Frankfurt (40 firms), Stuttgart (21 firms), Hamburg (57 firms), Munich (70 firms) and Berlin (48 firms). Moreover, the figure exemplarily illustrates the geographic distribution of regional holidays across Germany. Shown is the example of Epiphany, which is legally recognized only in the grey-shaded states of BadenWuerttemberg (118 firms), Bavaria (180 firms), and Saxony-Anhalt (3 firms).

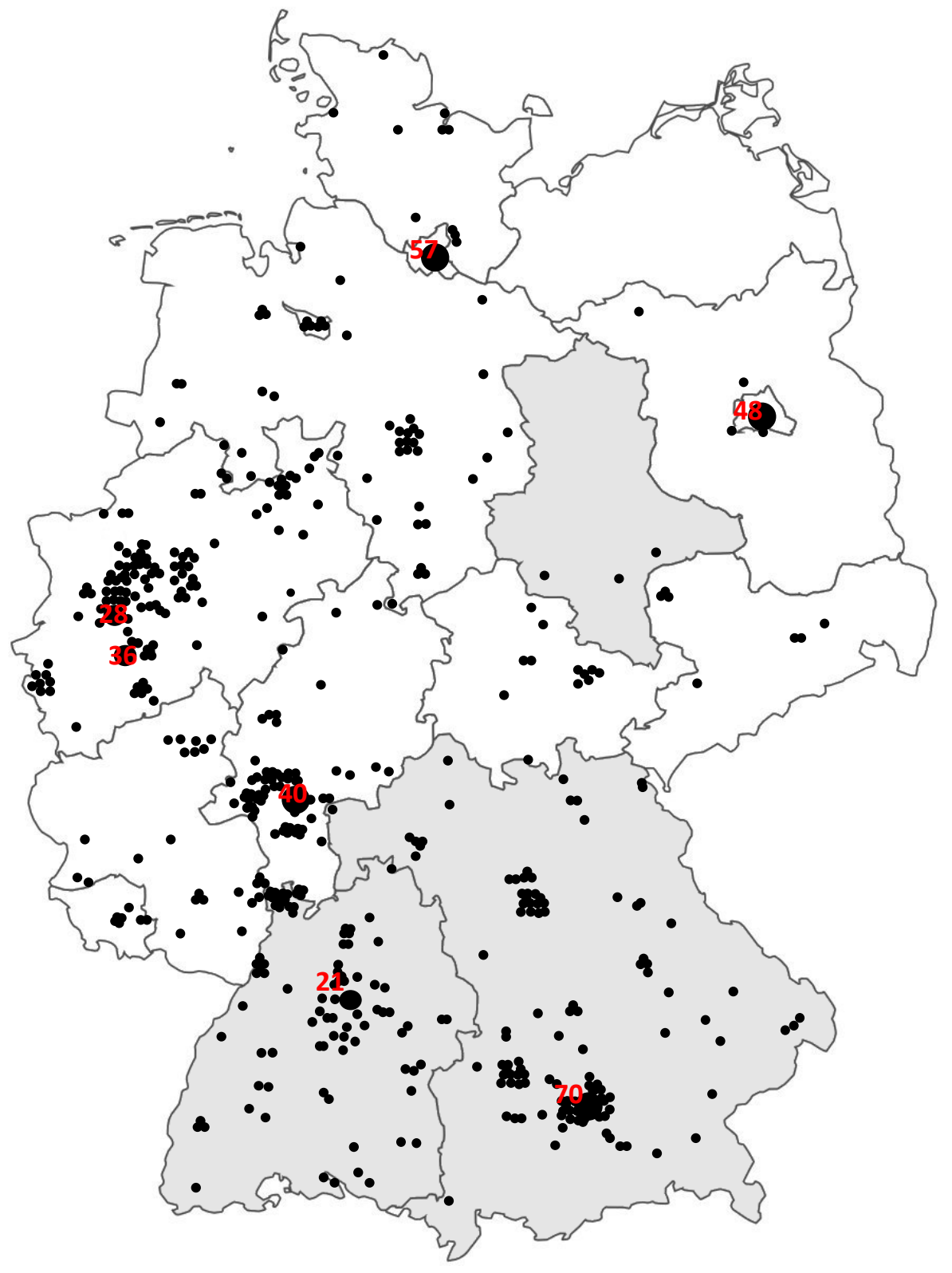




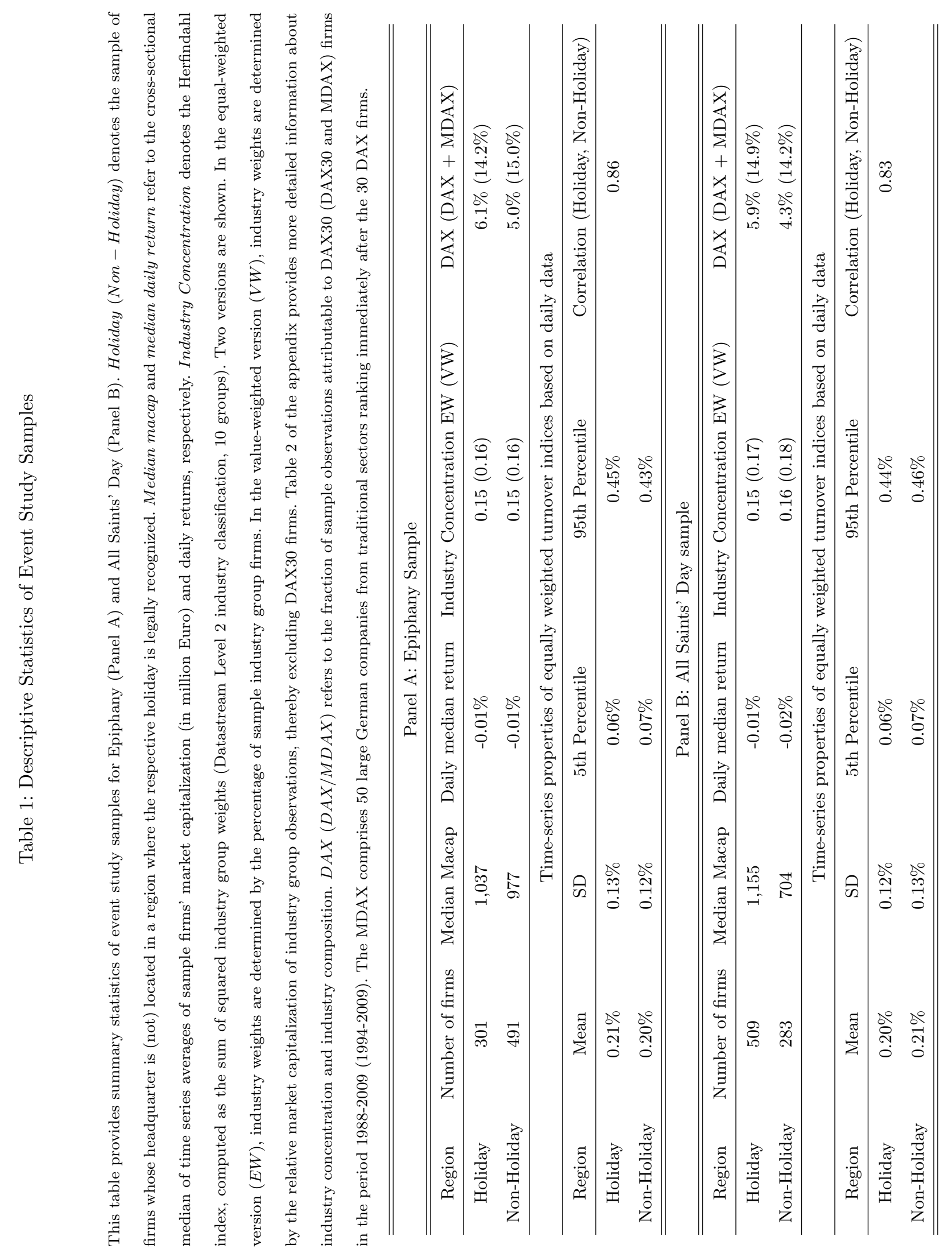




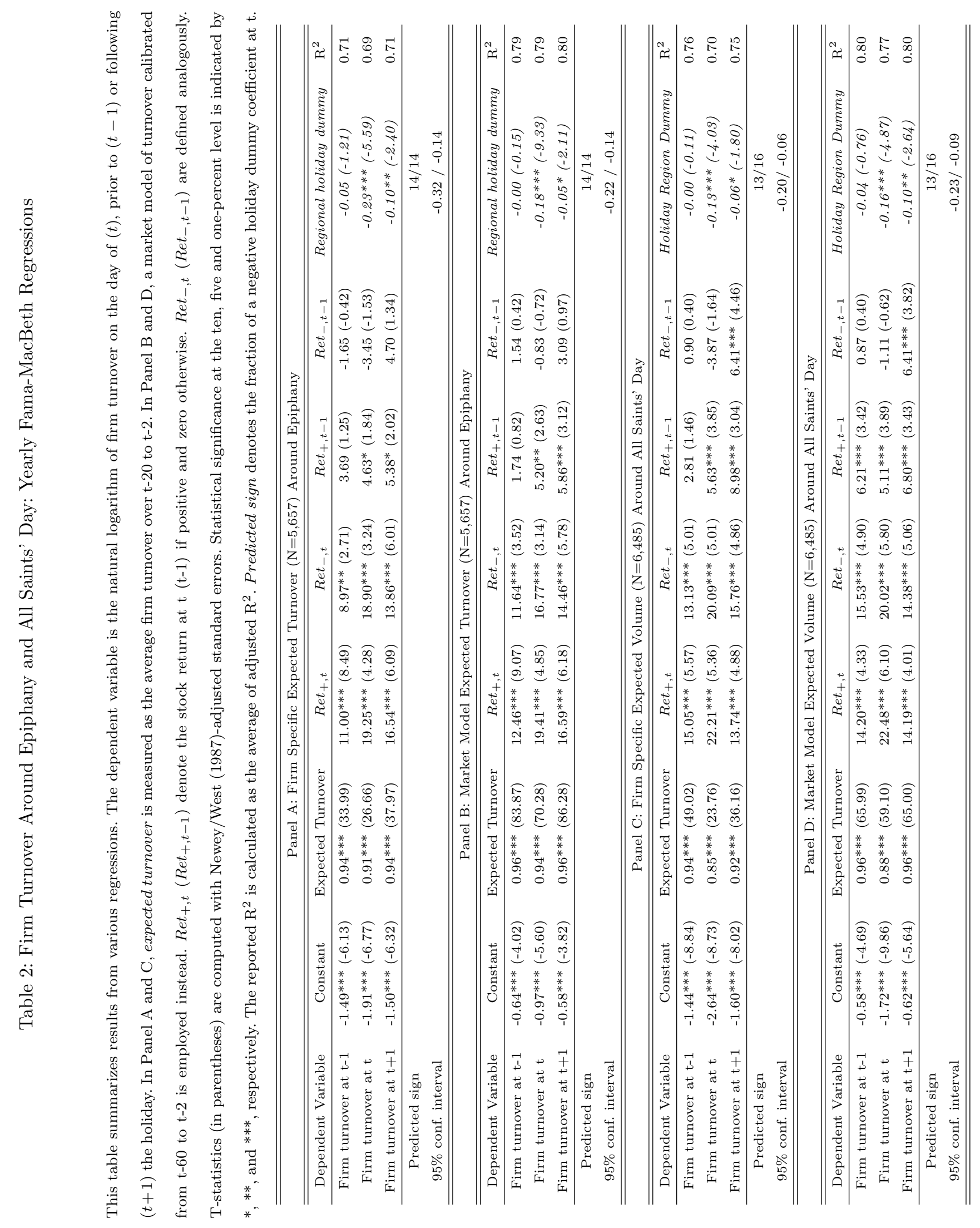


Table 3: Robustness Checks

This table displays the coefficient in front of the holiday dummy obtained from various regressions to test for

the robustness of our baseline results. T-statistics are reported in parentheses. Statistical significance at the ten, five and one-percent level is indicated by *, **, and ${ }^{* * *}$, respectively.

\begin{tabular}{|c|c|c|}
\hline & Epiphany & All Saints' Day \\
\hline \multicolumn{3}{|c|}{ Panel A: Mean and Median Factor Loadings on the Regional Holiday Dummy from Placebo Treatments } \\
\hline Firm specific expected turnover & Mean: -0.001, Median: -0.004 & Mean: 0.005, Median: 0.001 \\
\hline Market model expected turnover & Mean:0.007, Median: 0.009 & Mean: 0.005, Median: 0.006 \\
\hline \multicolumn{3}{|c|}{ Panel B: Alternative Pre-event Periods } \\
\hline Firm specific expected turnover in $\mathrm{t}-10$ to $\mathrm{t}-2$ & $-0.24^{* * *}(-5.54)$ & $-0.13^{* * *}(-3.45)$ \\
\hline Firm specific expected turnover in $\mathrm{t}-40$ to $\mathrm{t}-2$ & $-0.21^{* * *}(-5.02)$ & $-0.14^{* * *}(-3.78)$ \\
\hline Firm specific expected turnover in $\mathrm{t}-40$ to $\mathrm{t}-11$ & $-0.20 * * *(-5.28)$ & $-0.15^{* * *}(-4.14)$ \\
\hline Market model expected turnover in t-100 to t-2 & $-0.17^{* * *}(-7.20)$ & $-0.17^{* * *}(-3.70)$ \\
\hline Market model expected turnover in $\mathrm{t}-40$ to $\mathrm{t}-2$ & $-0.19^{* * *}(-9.04)$ & $-0.16^{* * *}(-5.41)$ \\
\hline Market model expected turnover in t-60 to t- 11 & $-0.17^{* * *}(-9.12)$ & $-0.16^{* * *}(-4.62)$ \\
\hline \multicolumn{3}{|c|}{ Panel C: Interacting Return Variables with Holiday Dummies } \\
\hline Firm specific expected turnover & $-0.29^{* * *}(-4.29)$ & $-0.17^{* * *}(-2.82)$ \\
\hline Market model expected turnover & $-0.22^{* * *}(-5.69)$ & $-0.21^{* * *}(-3.54)$ \\
\hline \multicolumn{3}{|c|}{$\begin{array}{l}\text { Panel D: Omitting Stocks With Zero Trading Volume on Event Day } \\
\end{array}$} \\
\hline Firm specific expected turnover & $-0.24^{* * *}(-11.48)$ & $-0.15^{* * *}(-4.84)$ \\
\hline Market model expected turnover & $-0.20^{* * *}(-15.10)$ & $-0.19^{* * *}(-6.23)$ \\
\hline \multicolumn{3}{|c|}{ Panel E: Using Ordinary Turnover } \\
\hline Firm specific expected turnover & $-0.02 \% * * *(-3.80)$ & $-0.02 \% * * *(-3.10)$ \\
\hline Market model expected turnover & $-0.02 \% * * *(-3.31)$ & $-0.02 \% * * *(-3.82)$ \\
\hline \multicolumn{3}{|c|}{ Panel F: Pooled Regression With Year Dummies and Standard Errors Clustered by Firm } \\
\hline Firm specific expected turnover & $-0.23^{* * *}(-4.73)$ & $-0.13^{* *}(-2.51)$ \\
\hline Market model expected turnover & $-0.19^{* * *}(-4.13)$ & $-0.16^{* * *}(-2.86)$ \\
\hline \multicolumn{3}{|c|}{ Panel G: Analysis Based on Metropolitan Areas } \\
\hline Firm specific expected turnover & $-0.22^{* * *}(-9.46)$ & $-0.13^{* * *}(-4.13)$ \\
\hline Market model expected turnover & $-0.18^{* * *}(-5.90)$ & $-0.17^{* * *}(-4.77)$ \\
\hline \multicolumn{3}{|c|}{ Panel H: Regional Holiday Effects on Corpus Christi (Since 2000, Econometric Approach as in Panel F) } \\
\hline & Firm specific expected turnover & Market model expected turnover \\
\hline & $-0.20^{* * *}(-2.67)$ & $-0.20^{* * *}(-3.61)$ \\
\hline \multicolumn{3}{|c|}{ Panel I: Carnival Monday } \\
\hline & Firm specific expected turnover & Market model expected turnover \\
\hline & $-0.05^{* *}(-2.38)$ & $-0.06^{* *}(-2.74)$ \\
\hline
\end{tabular}


Table 4: Tests for Cross-Sectional Differences in News Arrival

This table summarizes results from various tests aimed at detecting potential cross-sectional differences in news arrival between holiday and non-holiday firms at the day of the holiday (=t). Large firms (Small firms) refer to stocks with a market value larger (smaller) than the median stock, measured at the beginning of the year. Statistical significance at the ten, five and one percent level is indicated by ${ }^{*},{ }^{* *}$, and ${ }^{* * *}$, respectively. Panel A reports differences in shocks in absolute abnormal returns. To this end, daily absolute abnormal returns for each firm during t-5 to t+5, as obtained from a German version of the Carhart (1997) four factor model, are computed. Factor loadings are estimated from time-series regressions from t-66 to t-6. For both the holiday and the non-holiday sample, firm-specific shocks are computed as the absolute abnormal return at $\mathrm{t}$ minus the average absolute abnormal return in $t-5$ to $t+5$ (excluding $t$ ). The table reports the difference between the median shock value for the holiday sample and the median shock value for the non-holiday sample, averaged across years. Statistical significance is assessed by bootstrapping as described in footnote 11. Panel B reports the coefficient in front of the regional holiday dummy as obtained from pooled regressions of daily firm-specific abnormal search volume in Google on dummies for regional holidays, years and industry groups. Abnormal search volume is computed as the difference between the search volume at $t$ and the average search volume in $\mathrm{t}-10$ to t-2, divided by the standard deviation of search volume in this pre-event period. T-statistics are reported in parentheses. The last column reports p-values as obtained from an F-test of joint significance of all three holiday dummies. Panel $\mathrm{C}$ shows the average fraction of total analyst recommendations and reviews attributable to holiday firms at t. Only recommendations and reviews issued (not outstanding) on a given day are considered. In a similar way, the fraction holiday firms account for is also computed for every other day in $t-5$ to $t+5$. These values are pooled to construct an empirical benchmark distribution of analyst coverage in a nearby period. Values in parentheses represent the percentiles of this distribution as achieved at t. A higher percentile indicates that holiday firm recommendations account for a larger fraction of the total number of recommendations. In the value-weighted (equal-weighted) analysis, multiple recommendations of the same firm are considered as multiple observations (single observation).

\begin{tabular}{ccccc}
\hline \hline \multicolumn{5}{c}{ Panel A: Differences in Shocks in Absolute Abnormal Returns } \\
\hline \hline Dependent Variable & Epiphany & All Saints' Day & Corpus Christi & Pooled \\
Difference in shock variable: All firms & $-0.05 \% *$ & $-0.02 \%$ & $-0.02 \%$ & $-0.03 \%$ \\
Difference in shock variable: Large firms & $-0.07 \%^{*}$ & $-0.01 \%$ & $-01 \%$ & $-0.03 \%$ \\
Difference in shock variable: Small firms & $-0.02 \%$ & $-0.05 \%$ & $-0.03 \%$ & $-03 \%$ \\
\hline \hline Panel B: Abnormal Search Frequencies for Firm Names in Google & All Saints' Day & Corpus Christi & P-value joint sign. \\
\hline \hline Dependent Variable & Epiphany & $-0.15(-1.40)$ & $-0.19(-1.42)$ & 0.19 \\
Shocks in online search queries: All firms & $-0.13(-0.61)$ & $-0.33(-1.02)$ & $-0.20(-0.40)$ & 0.16 \\
Shocks in online search queries: Large firms & $-0.26(-0.52)$ & $-0.08(-1.14)$ & \\
Shocks in online search queries: Small firms & $-0.12(-0.58)$ & $-0.16(-1.55)$ & -0.19 \\
\hline \hline Panel C: Fraction of Holiday Firm Analysts Recommendations & All Saints' Day & Corpus Christi \\
\hline \hline Dependent Variable & Epiphany & $68.57 \%(59)$ & $81.51 \%(40)$ \\
Value-weighted fraction of recommendations & $40.34 \%(64)$ & $82.57 \%(43)$ \\
Equally-weighted fraction of recommendations & $40.37 \%(58)$ & $69.90 \%(62)$ & $87.87 \%(54)$ \\
Value-weighted fraction of reviews & $41.67 \%(66)$ & $63.64 \%(40)$ & $89.23 \%(54)$ \\
Equally-weighted fraction of reviews & $43.08 \%(72)$ & $63.84 \%(44)$ & \\
\hline \hline
\end{tabular}




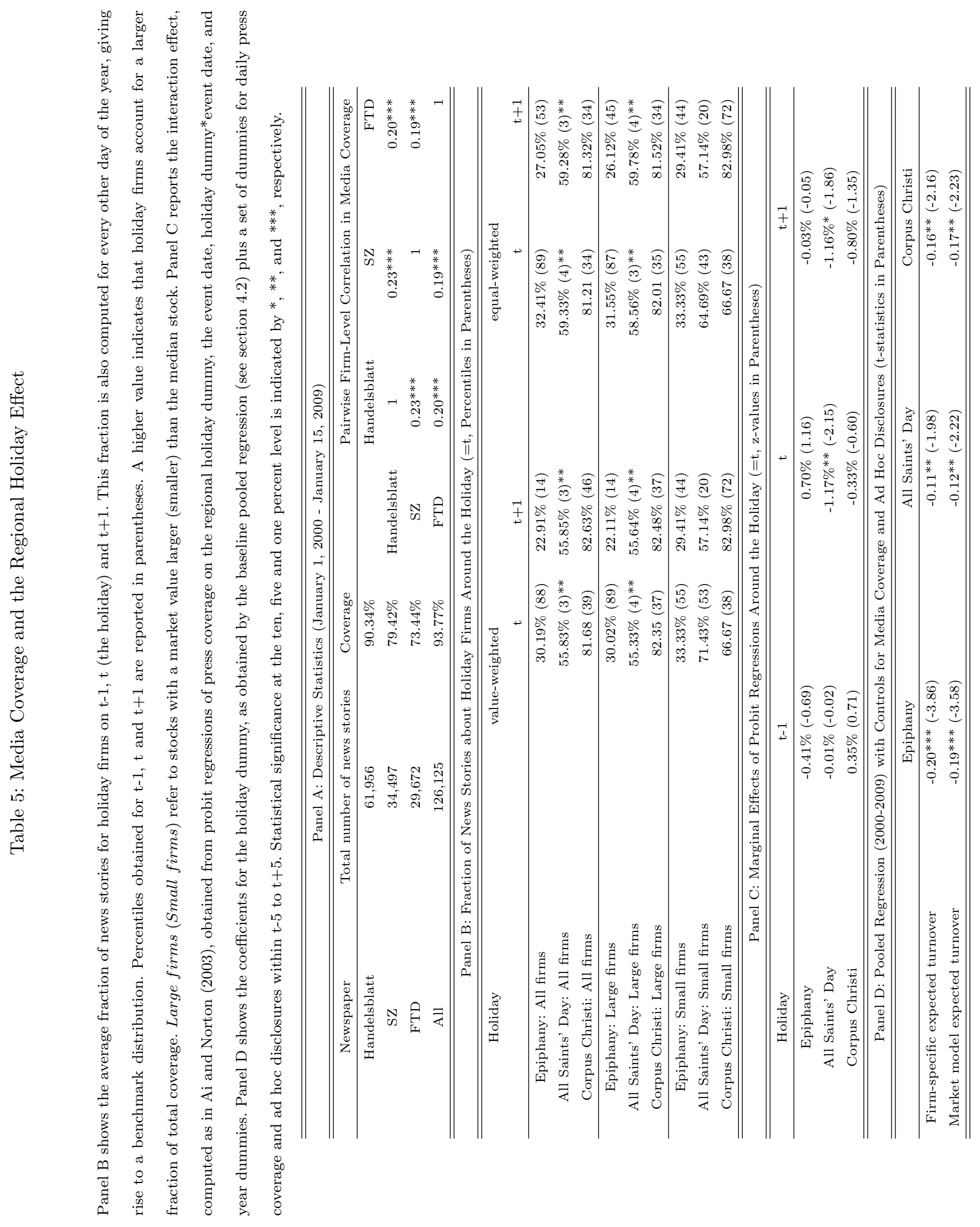




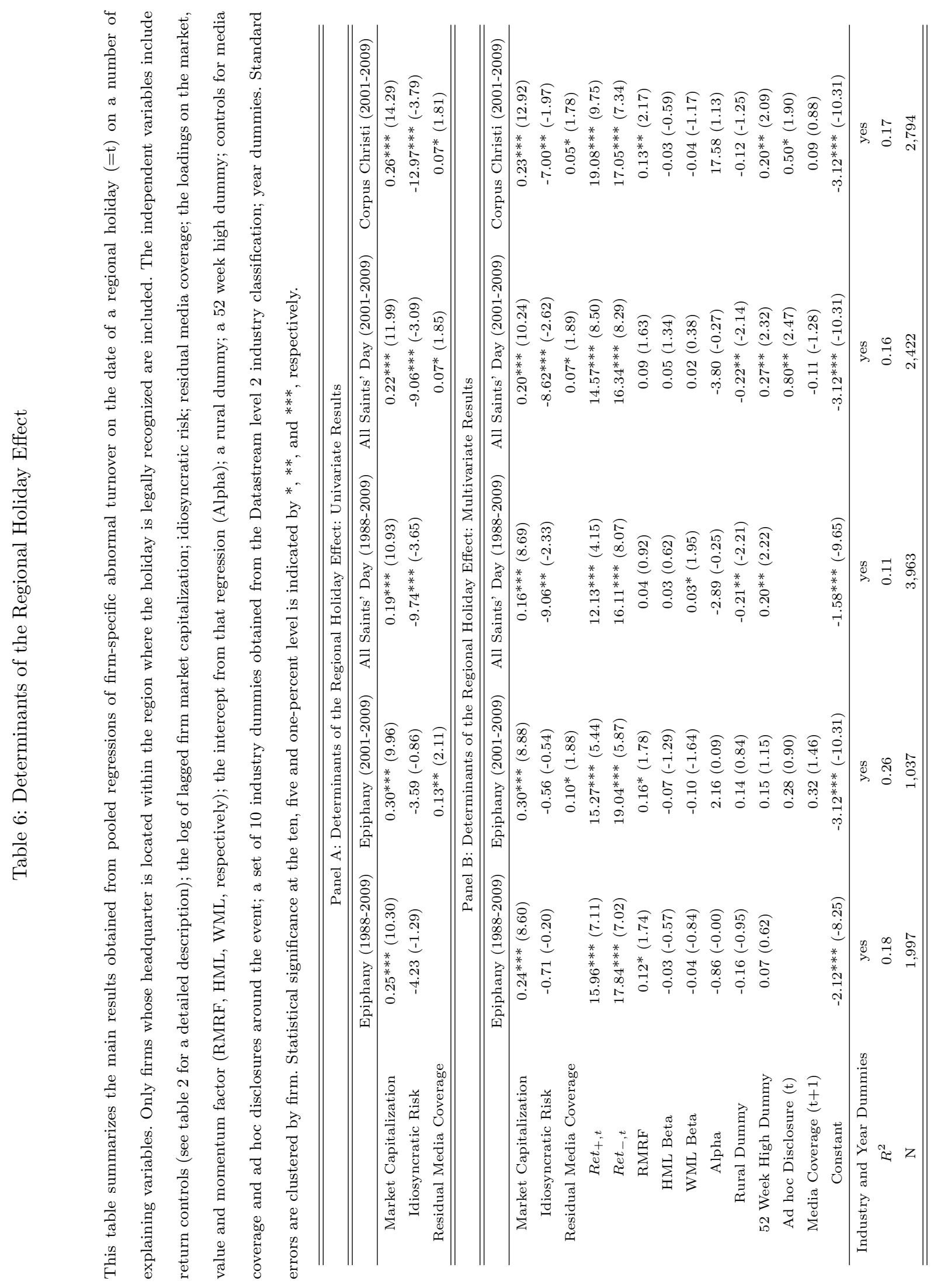




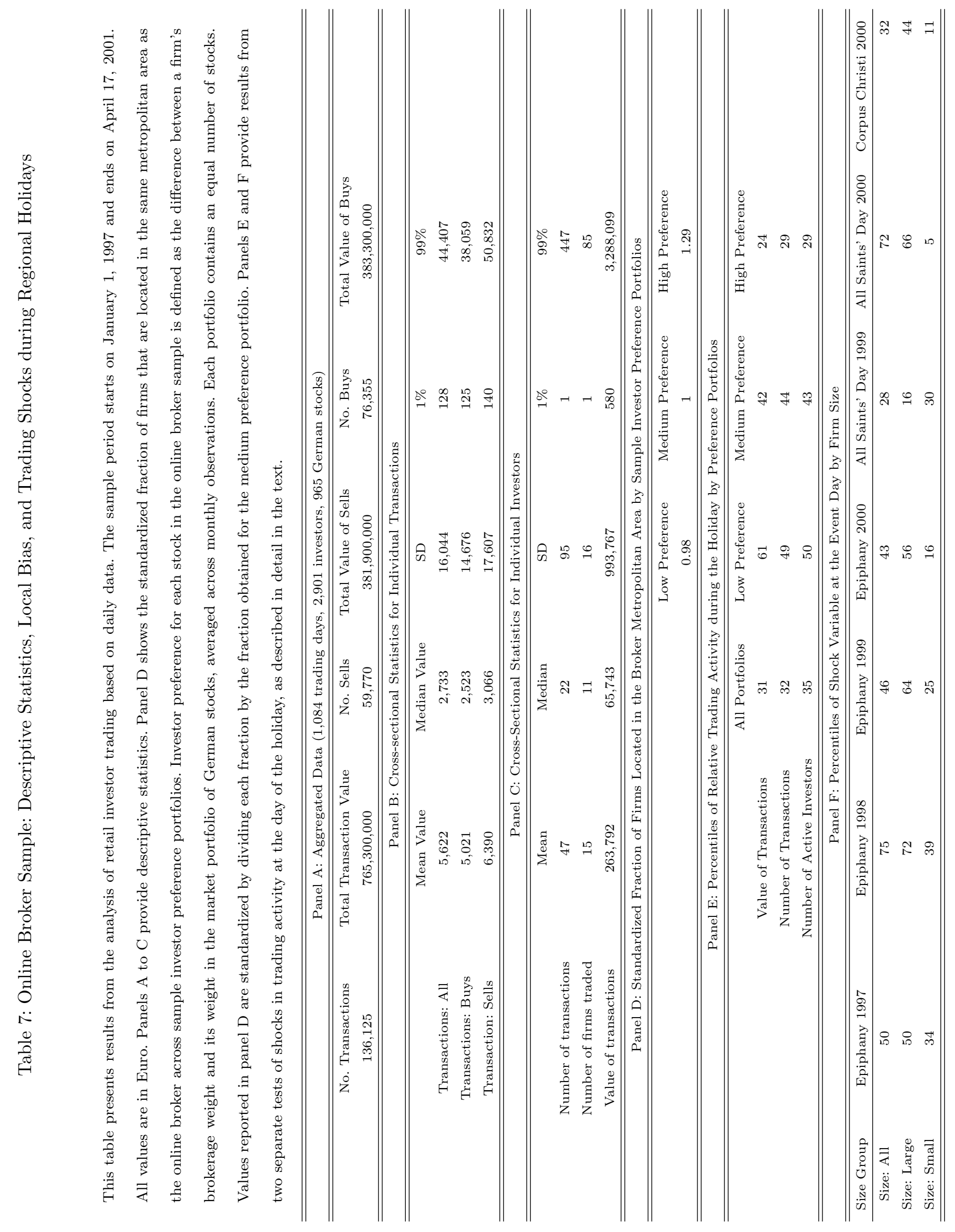




\title{
Appendix for "The Trading Volume Impact of Local Bias:
}

\author{
Evidence from a Natural Experiment"
}

\author{
Heiko Jacobs and Martin Weber*
}

June 1, 2011

\begin{abstract}
This appendix contains explanations and tables that supplement the analysis in the paper. Table 1 gives an overview of the data sets used. Table 2 illustrates the distribution of legally recognized holidays across German states. Table 3 provides descriptive statistics of the stock market data. Table 4 displays the distribution of industry groups across samples. Table 5 illustrates the construction of the factors for size, value and momentum. Table 6 provides further evidence on the level of differences in shocks in absolute abnormal returns between holiday and non-holiday firms. Figure 1 compares the cumulative distribution functions of shock variables on Epiphany. Table 7 compares individual investor characteristics in holiday and non-holiday regions.
\end{abstract}

*Heiko Jacobs is from the Lehrstuhl für Bankbetriebslehre, Universität Mannheim, L 5, 2, 68131 Mannheim. E-Mail: jacobs@bank.bwl.uni-mannheim.de. Martin Weber is from the Lehrstuhl für Bankbetriebslehre, Universität Mannheim, L 5, 2, 68131 Mannheim, and CEPR, London. E-Mail: weber@bank.bwl.uni-mannheim.de. 


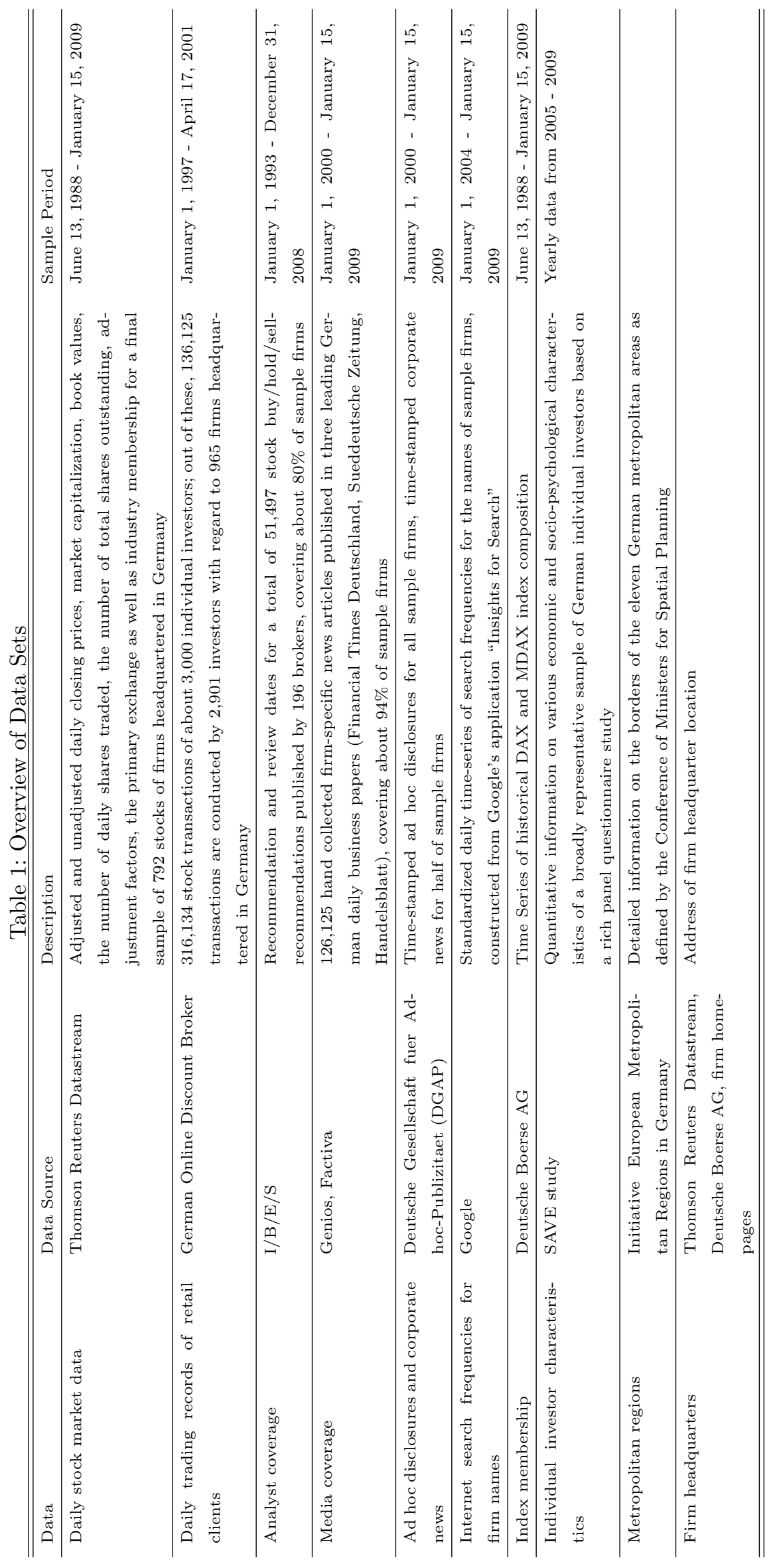




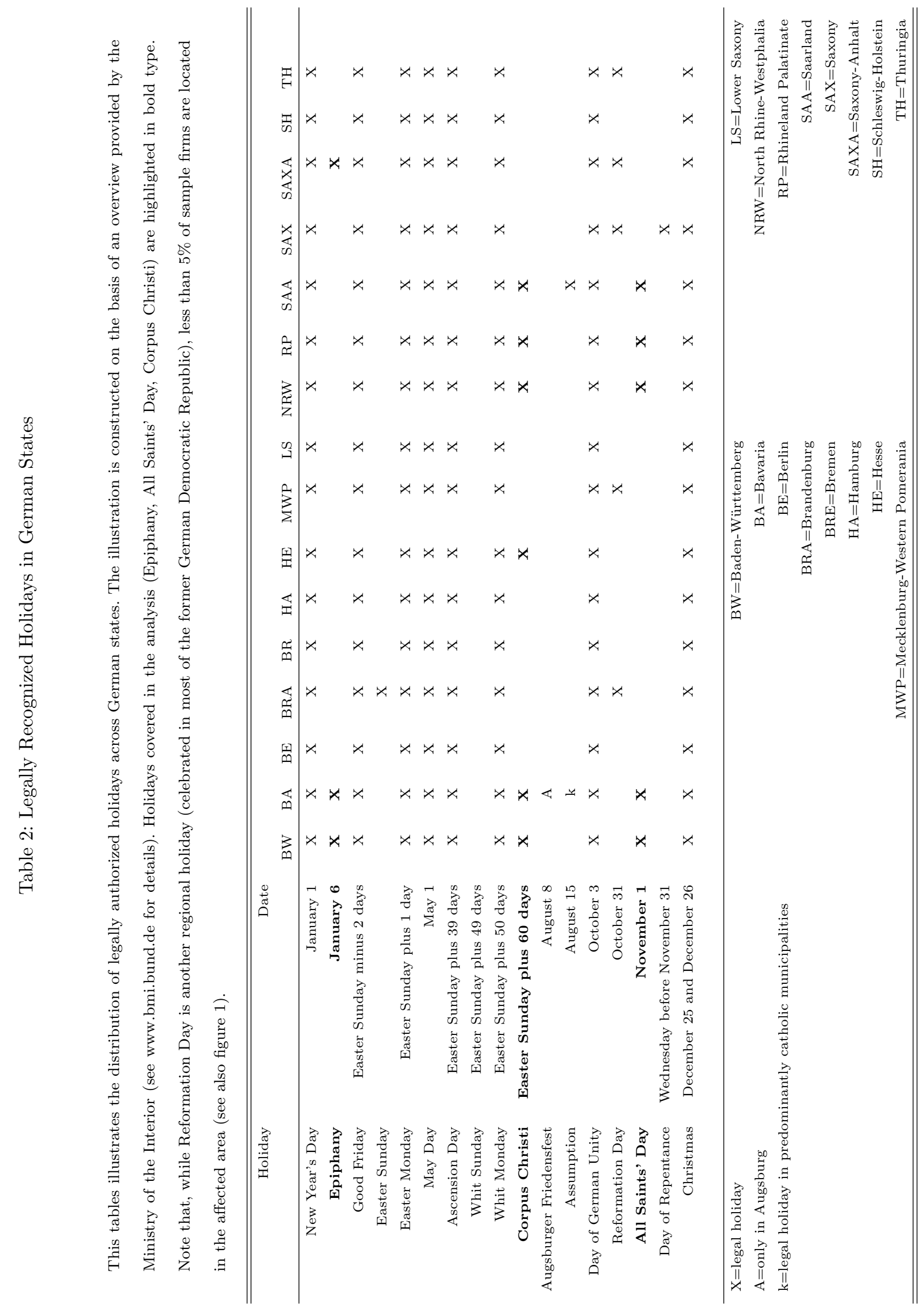




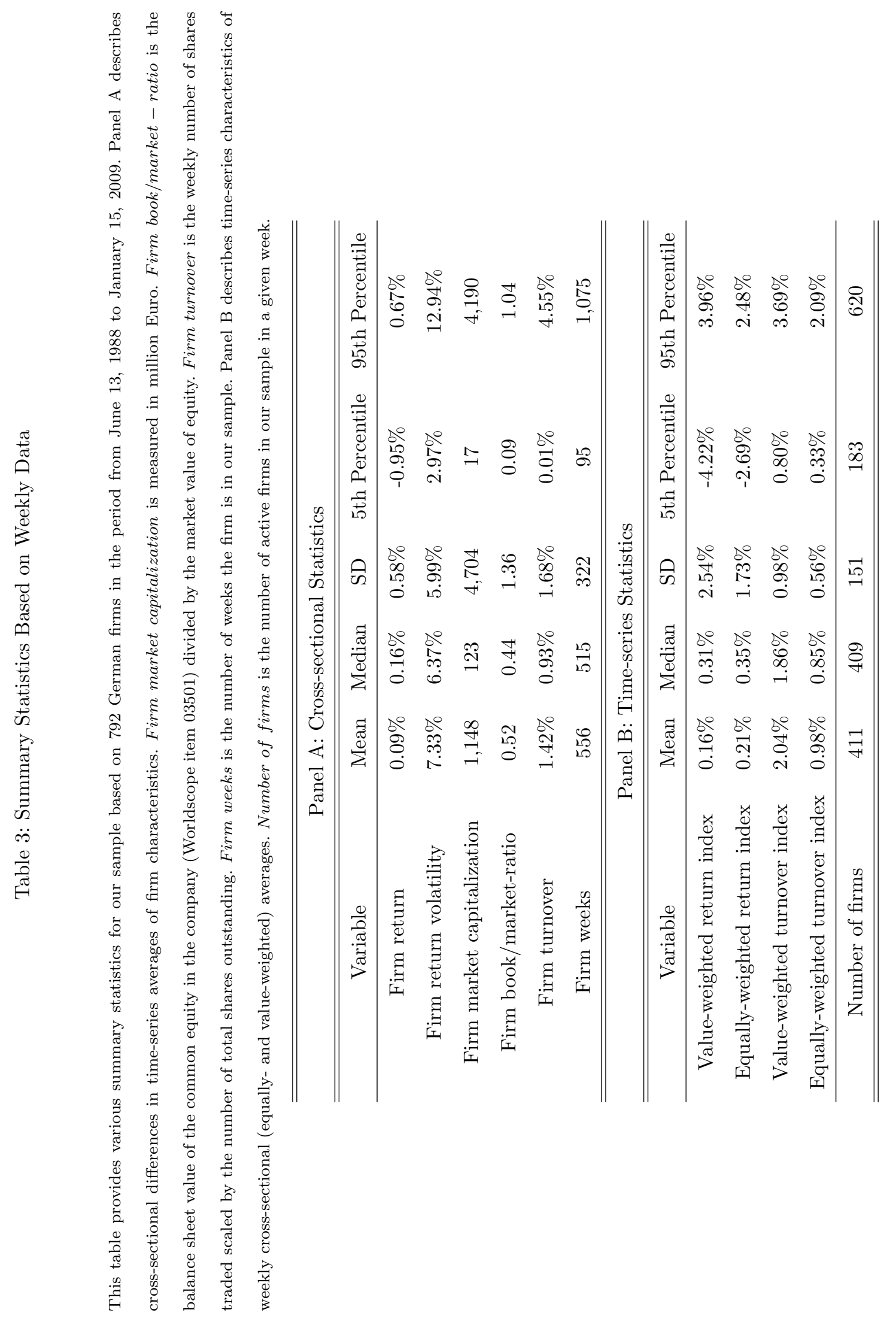




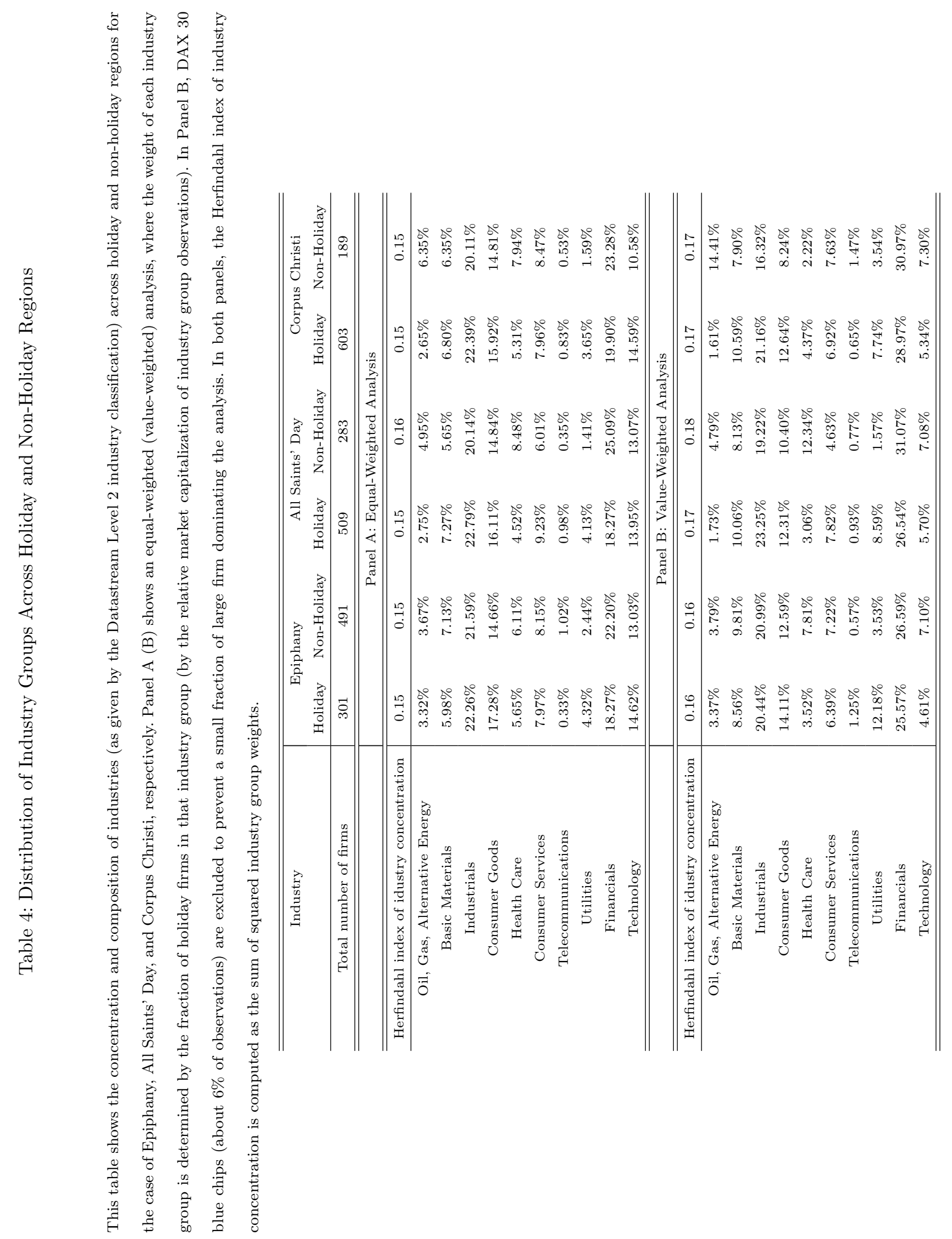




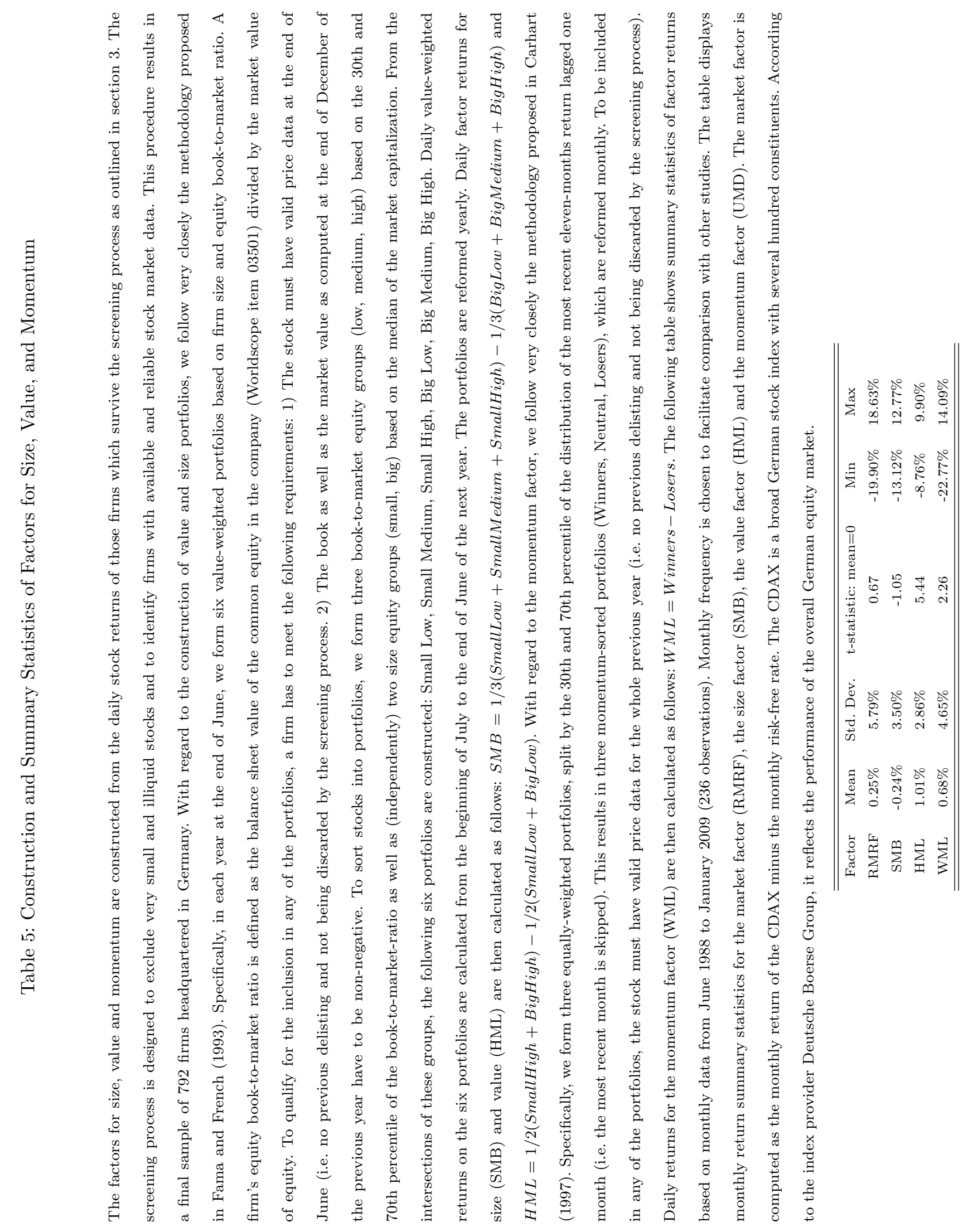


Table 6: Difference in Shocks in Absolute Abnormal Returns: Further Evidence

This table provides supplementary material for the test on differences in shocks in absolute abnormal returns, as described in section 4.3 of the paper. Panel A reports differences in mean shocks in absolute abnormal returns. To this end, daily absolute abnormal returns for each firm during t-5 to $t+5$, as obtained from a German version of the Carhart (1997) four factor model, are computed. Factor loadings are estimated from time-series regressions from t-66 to t-6. For both the holiday and the non-holiday sample, firm-specific shocks are computed as the absolute abnormal return at $\mathrm{t}$ minus the average absolute abnormal return in $\mathrm{t}-5$ to $\mathrm{t}+5$ (excluding t). The table reports the difference between the mean shock value for the holiday sample and the mean shock value for the non-holiday sample, averaged across years. To mitigate the effect of extreme outliers, we winsorize the data at the $1 \%$ and $99 \%$ level before computing the mean. This is done for the holiday and non-holiday sample in each year separately. Statistical significance is assessed by bootstrapping as described in footnote 12. Large firms (Small firms) refer to stocks with a market value larger (smaller) than the median stock, measured at the beginning of the year. Statistical significance at the ten, five and one percent level is indicated by ${ }^{*}, *$, and ${ }^{* * *}$, respectively. Panel B compares the frequency of extreme return events on the event day. To this end, all holiday (non-holiday) firm-level shocks are pooled. Shock variable at least $0 \%$ means that the idiosyncratic component of the stock's return on the event day has at least the same importance as on average in a nearby benchmark period ( $t-5$ to $t+5$, excluding $t$ ). The odds ratio is computed as the ratio of the fraction of extreme events for holiday firms and the fraction of extreme events for non-holiday firms.

\begin{tabular}{|c|c|c|c|c|}
\hline \multicolumn{5}{|c|}{ Panel A: Difference in Mean Shocks in Absolute Abnormal Returns } \\
\hline Dependent Variable & Epiphany & All Saint's Day & Corpus Christi & Pooled \\
\hline Abnormal absolute return: All firms & $-0.08 \% *$ & $0.02 \%$ & $-0.07 \%$ & $-0.04 \%$ \\
\hline Abnormal absolute return: Large firms & $-0.09 \% * *$ & $0.00 \%$ & $-0.08 \%$ & $-0.06 \% *$ \\
\hline Abnormal absolute return: Small firms & $-0.07 \%$ & $0.02 \%$ & $-0.06 \%$ & $-0.03 \%$ \\
\hline \multicolumn{5}{|c|}{ Panel B: Frequency of Extreme Return Events on the Event Day } \\
\hline \multicolumn{2}{|c|}{ Event } & Holiday Firm Observations & Non-Holiday Firm Observations & Odds Ratio \\
\hline \multicolumn{2}{|c|}{$\%$ of Observations with Shock Variable at least $0 \%$} & $34.57 \%$ & $37.09 \%$ & 0.93 \\
\hline \multicolumn{2}{|c|}{$\%$ of Observations with Shock Variable at least $1 \%$} & $15.22 \%$ & $16.04 \%$ & 0.95 \\
\hline \multicolumn{2}{|c|}{$\%$ of Observations with Shock Variable at least $2 \%$} & $7.63 \%$ & $8.68 \%$ & 0.88 \\
\hline
\end{tabular}


Figure 1: Comparison of cumulative distribution functions of shock variables on Epiphany

The following graph is intended to illustrate the economic magnitude of the difference in shock variables between holiday and non-holiday firms (see section 4.3 of the paper). As the largest difference is observed for Epiphany (see panel A of table 4 in the paper ), we employ the following procedure. For each year in which Epiphany falls on a trading day, we compute the empirical cumulative probably distribution of the shock variable for holiday firms and separately for non-holiday firms. To obtain an overall distribution, we then average the resulting percentiles across time. This approach resembles the procedure used in the analysis relied on in the paper, which aimed at obtaining an estimate for the shock variable of the median firm. The following graph shows the two cumulative distribution functions. For better readability, only values above the 5th percentile and below the 95th percentile are displayed.

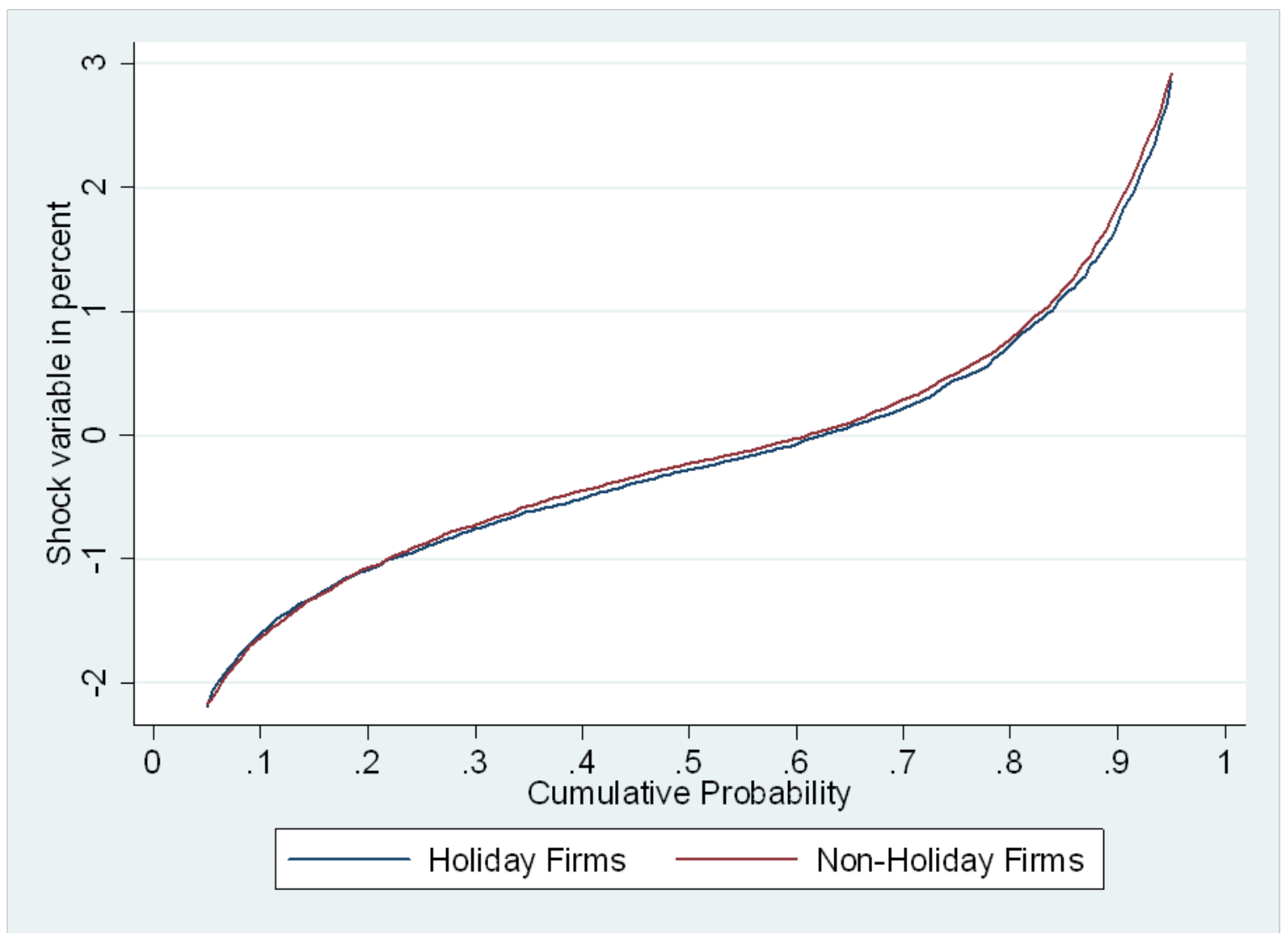




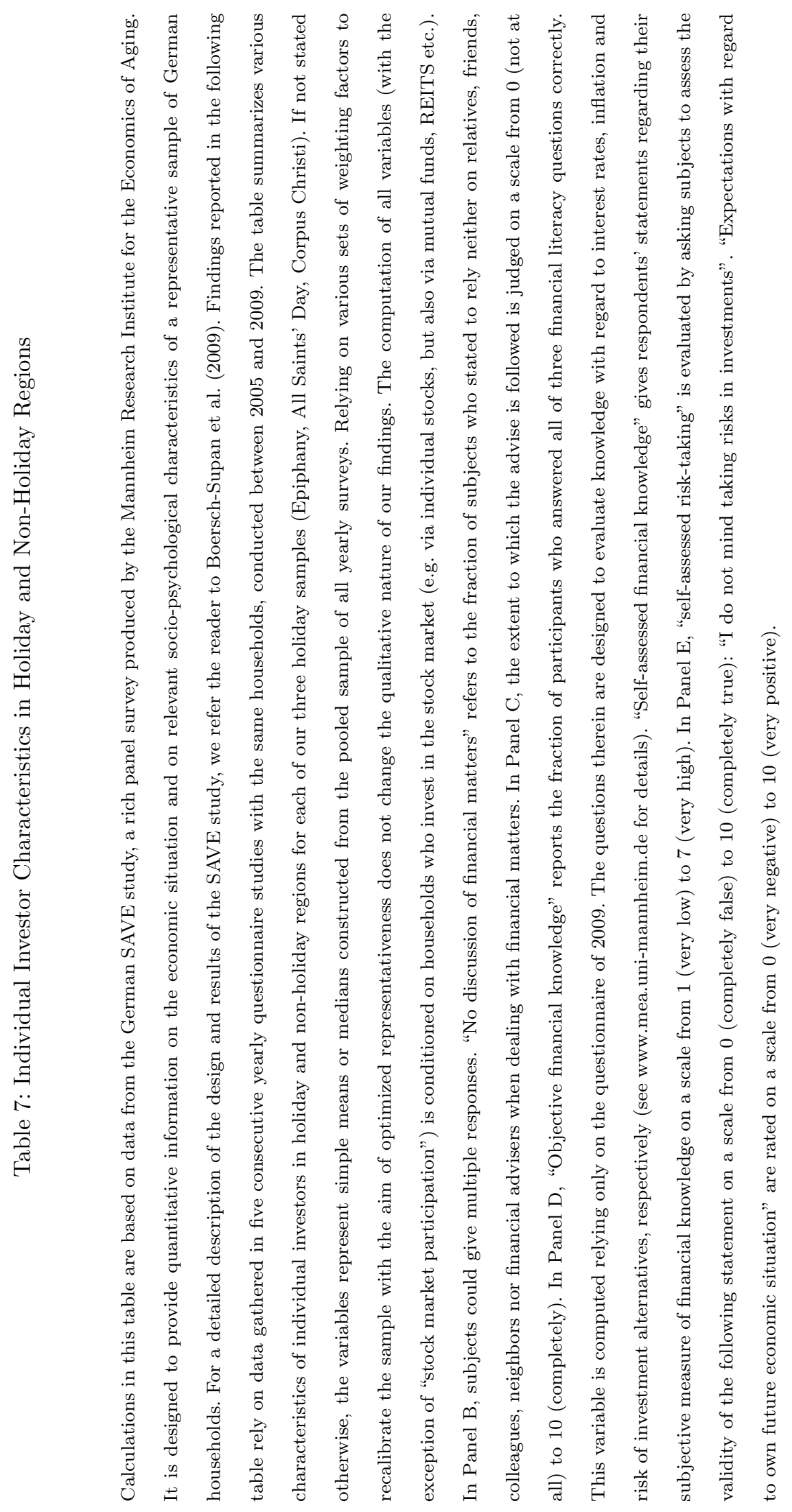




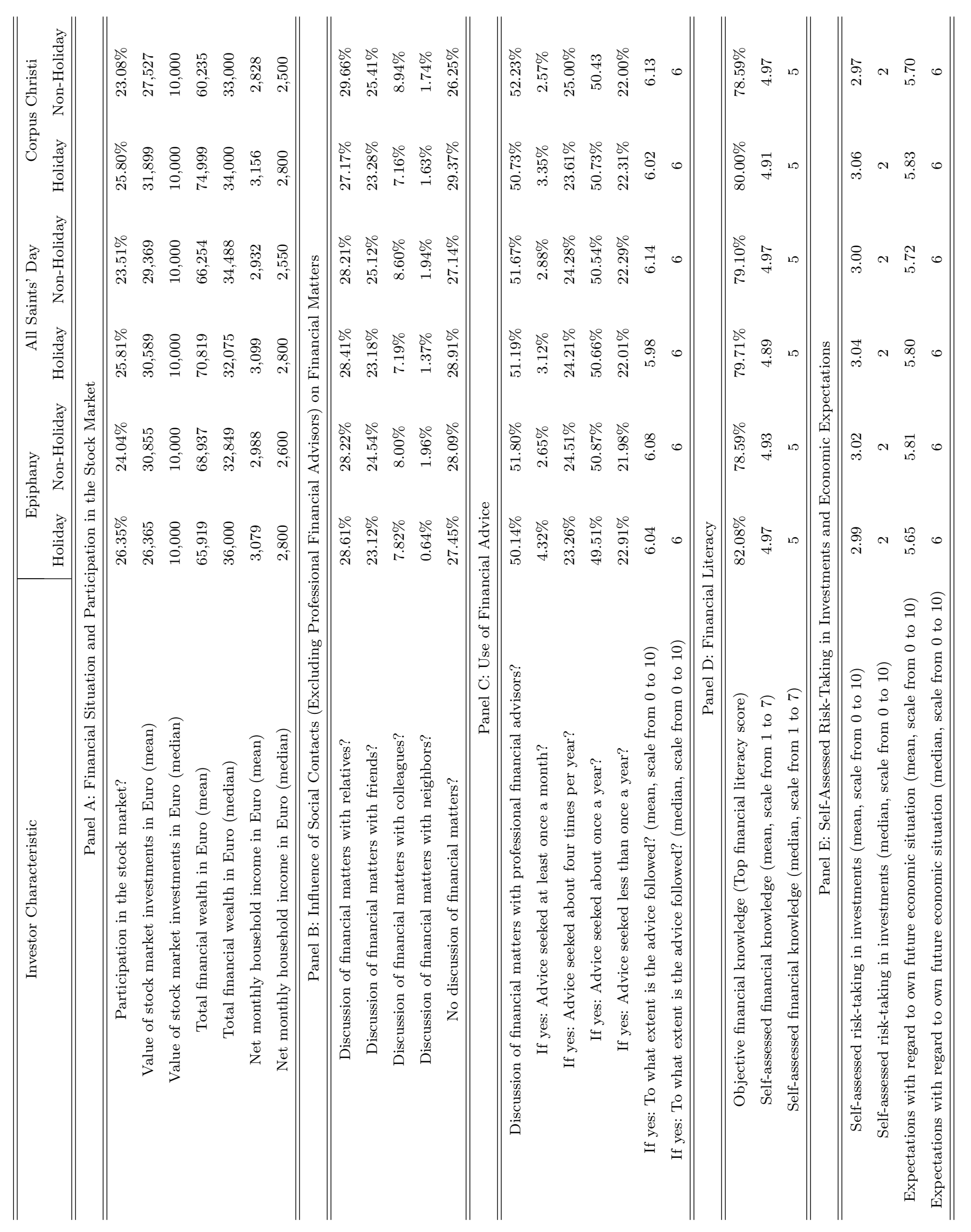

